Review

\title{
Graphene-Based Composites as Catalysts for the Degradation of Pharmaceuticals
}

\author{
Olalekan C. Olatunde ${ }^{1,2}$ (D) and Damian C. Onwudiwe ${ }^{1,2, * \mathbb{D}}$
}

1 Material Science Innovation and Modelling (MaSIM) Research Focus Area, Faculty of Natural and Agricultural Sciences, Mafikeng Campus, North-West University, Private Bag X2046, Mmabatho 2735, South Africa; Olalekan.olatunde@eksu.edu.ng

2 Department of Chemistry, School of Physical and Chemical Sciences, Faculty of Natural and Agricultural Sciences, Mafikeng Campus, North-West University, Private Bag X2046, Mmabatho 2735, South Africa

* Correspondence: Damian.Onwudiwe@nwu.ac.za; Tel.: +27-18-389-2545; Fax: +27-18-389-2420

Citation: Olatunde, O.C.; Onwudiwe, D.C. Graphene-Based Composites as Catalysts for the Degradation of Pharmaceuticals. Int. J. Environ. Res. Public Health 2021, 18, 1529. https://doi.org/10.3390/ ijerph18041529

Academic Editor: Gerardo León Received: 5 December 2020

Accepted: 27 January 2021

Published: 5 February 2021

Publisher's Note: MDPI stays neutral with regard to jurisdictional claims in published maps and institutional affiliations.

Copyright: (c) 2021 by the authors. Licensee MDPI, Basel, Switzerland. This article is an open access article distributed under the terms and conditions of the Creative Commons Attribution (CC BY) license (https:// creativecommons.org/licenses/by/ $4.0 /)$.
Abstract: The incessant release of pharmaceuticals into the aquatic environment continues to be a subject of increasing concern. This is because of the growing demand for potable water sources and the potential health hazards which these pollutants pose to aquatic animals and humans. The inability of conventional water treatment systems to remove these compounds creates the need for new treatment systems in order to deal with these class of compounds. This review focuses on advanced oxidation processes that employ graphene-based composites as catalysts for the degradation of pharmaceuticals. These composites have been identified to possess enhanced catalytic activity due to increased surface area and reduced charge carrier recombination. The techniques employed in synthesizing these composites have been explored and five different advanced oxidation processesdirect degradation process, chemical oxidation process, photocatalysis, electrocatalyis processes and sonocatalytic/sono-photocatalytic processes-have been studied in terms of their enhanced catalytic activity. Finally, a comparative analysis of the processes that employ graphene-based composites was done in terms of process efficiency, reaction rate, mineralization efficiency and time required to achieve $90 \%$ degradation.

Keywords: pharmaceuticals; advanced oxidation process; graphene; composites; reactive radicals

\section{Introduction}

Pharmaceuticals are compounds that are produced for the purpose of usage as medicinal drugs. They remain however as persistent, biologically active compounds which could be detected in drinking and surface waters due to their incomplete removal by conventional processes [1]. These materials have received much attention recently due to their health and environmental implication [2-4]. The design of pharmaceuticals is such that when taken even at low concentrations, they can effect physiological changes in humans and animals. These compounds, when excreted either as metabolites or in an unchanged state, remain in the environment for a long time because they are not biologically degraded or reduced [5,6]. In aquatic environments, direct discharge of untreated and treated wastewater from treatment plants are the major source of pharmaceuticals, while terrestrial runoff from agricultural fields, aquaculture facilities and livestock farms are some of the secondary sources as shown in Figure 1 [7,8]. Aquatic channels act as transport routes for pharmaceuticals and their bioaccumulation is mainly due to their lipophilic character, although other factors such as animal homeostasis, metabolism and inhalation exposure are also important in understanding their accumulation in organisms [9-12]. Compared to other organic contaminants, hydrophobic interactions are not the main influencing parameter on the partitioning dynamics of most pharmaceuticals. Other factors including cation exchange, surface complexation, hydrogen bonding and cation bridging also play vital roles. Thus, modelling approaches that have been created for other organic contaminants 
such as persistent organic pollutants are inappropriate for assessing the environmental risks of pharmaceuticals [13].

The increasing surge in the global consumption of pharmaceuticals with the global pharmaceutical market worth expected to reach $\$ 1170$ billion in 2021 from $\$ 935$ billion in 2017. This implies that concerns over the pollution of the environment by the discharge of different types of pharmaceuticals will continue to grow. This account for them being tagged as part of the emerging anthropogenic hazard pollutants [14,15]. Also, their presence in the environment is due mainly to the inability of treatment plants to completely eliminate them. This, consequently, has led to their detection at concentration range of ng/L to $\mu \mathrm{g} / \mathrm{L}$ in surface water, tap water and ground water [16-18]. The increase in the concentration of pharmaceuticals in the water system, implies that the reuse of treated water, which has been suggested as the adequate solution for the sustainability of water resource is also under serious treat [19].

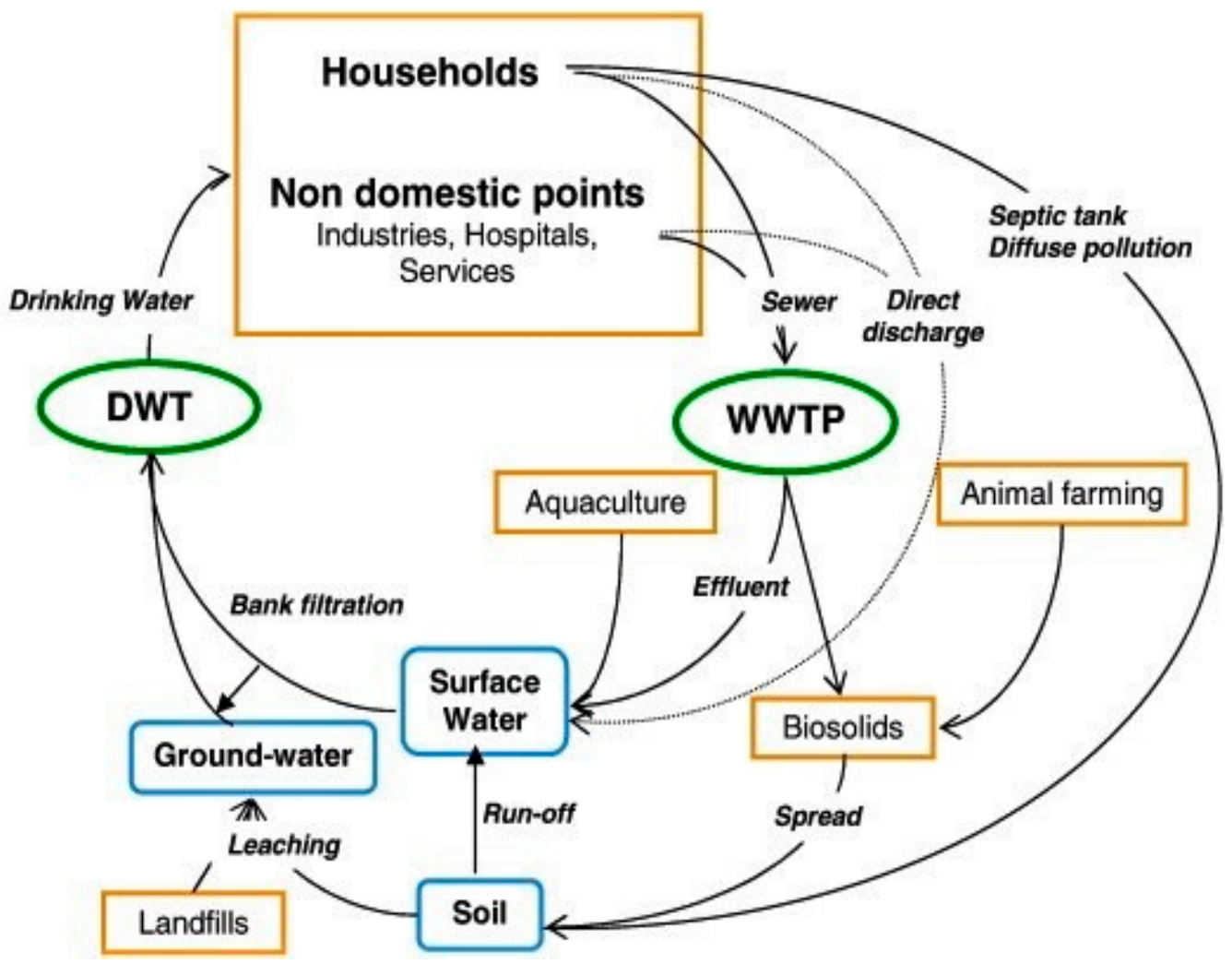

Figure 1. Origins of pharmaceuticals and their environmental routes (WWTP—wastewater treatment plant; DWT—drinking water treatment). Reprinted form Sayadi, et al. [20].

Pharmaceuticals and their by-products could be classified into 24 therapeutic classes, with anti-inflammatory drugs (NSAIDs) (e.g., ibuprofen, gemfibrozil and diclofenac), antibiotics (e.g., sulfamethoxazole and trimethoprim), anticonvulsants (e.g., carbamazepine) and lipid regulators (propranolol, metoprolol, nadolol) being the four most studied categories. Increasing information on the potential chronic or acute effects of pharmaceuticals on the ecosystem and living organisms have begun to emerge recently. Estrogen acts as endocrine modulators or disruptors and can have adverse effect on reproductive and sexual development like feminization of male fishes even at $\mathrm{ng} / \mathrm{L}$ level [18,21]. Diclofenac has been indicted for its effect on mammalian kidney and the disappearance of the Oriental White backed Vulture in India and Pakistan [22]. The increased resistance to antimicrobial agents is another risk associated with the presence of pharmaceuticals in the environment [23]. Table 1 presents some therapeutic classes of pharmaceuticals with their acute toxicity level and concentrations reported in the environment. 
Table 1. Some therapeutic classes of pharmaceuticals, toxicity level and their level of detection in the environment.

\begin{tabular}{|c|c|c|c|c|c|c|}
\hline Therapeutic Class & Example & Structure & $\begin{array}{c}\text { Acute Toxicity } \\
\text { Level/Test } \\
\text { Organism }\end{array}$ & $\begin{array}{l}\text { Detected Level in } \\
\text { the Environment }\end{array}$ & Matrix/Country & Ref. \\
\hline $\begin{array}{c}\text { Anti- } \\
\text { inflammatories }\end{array}$ & Diclofenac & & $90 \mu \mathrm{g} / \mathrm{L}$; fish & $0.44-7.1 \mu \mathrm{g} / \mathrm{L}$ & $\begin{array}{l}\text { Municipality } \\
\text { treatment plant }\end{array}$ & {$[24,25]$} \\
\hline Antibiotics & Ciprofloxacin & & 84-1000 mg/L; fish & $6.5-31 \mathrm{mg} / \mathrm{L}$ & WWTPs/India & [26] \\
\hline Antiepileptics & Carbamazepine & & $\begin{array}{c}0.01 \mu \mathrm{g} / \mathrm{L} \\
\text { invertebrate }\end{array}$ & $425-3500 \mathrm{ng} / \mathrm{L}$ & $\begin{array}{c}\text { Ground } \\
\text { water/UK }\end{array}$ & {$[27,28]$} \\
\hline Lipid regulator & Propranolol & & $\begin{array}{l}1.3-1.7 \mathrm{mg} / \mathrm{L} ; \\
\text { invertebrate }\end{array}$ & $20-92 \mathrm{ng} / \mathrm{L}$ & WWTPs/Canada & {$[29,30]$} \\
\hline Hormones & $17 \beta$-Estradiol & & $\begin{array}{l}1500 \mu \mathrm{g} / \mathrm{L} ; \\
\text { invertebrate }\end{array}$ & 3-11 ng/L & $\begin{array}{c}\text { Surface } \\
\text { water/China }\end{array}$ & {$[31,32]$} \\
\hline Anticancer & Tamoxifen & & - & $27-212 \mathrm{ng} / \mathrm{L}$ & $\begin{array}{c}\text { Surface } \\
\text { water/UK }\end{array}$ & [33] \\
\hline Cardiovascular & Metoprolol & & $\begin{array}{c}\text { 43.0-47.4 mg/L; } \\
\text { Ceriodaphnia dubia }\end{array}$ & 20-116 ng/L & $\begin{array}{c}\text { Surface } \\
\text { water/Hungry }\end{array}$ & [34] \\
\hline Antidiabetics & Metformin & & - & $100-1700$ ng/L & $\begin{array}{c}\text { Surface } \\
\text { water/Germany }\end{array}$ & [35] \\
\hline
\end{tabular}

Since conventional water and wastewater treatment processes (WWTP) are incapable of completely removing pharmaceuticals, it is therefore important for advanced treatment techniques to be incorporated into WWTPs. Some of the advanced processes that have been explored for the removal of pharmaceuticals include chemical oxidation processes, membrane technologies and adsorption [36]. Membrane technologies and adsorption process are economical physical techniques, with relative ease of handling; however, these processes are highly material and energy intensive [37] and the problem of membrane retentate and spent adsorbent disposal means there is high possibility of reintroducing the removed contaminants back into the environment. Thus much focus has beenon oxidation processes, in which contaminants are degraded by highly reactive radical species species generated within the system. These processes are referred to as advanced oxidation process (AOPs) and as shown in Figure 2, there is a continual growth in the body of literature on their application in pharmaceutical degradation. Advanced oxidation process is an aqueous phase oxidation technique that is based on the action of highly reactive species such as hydroxyl radical $\left.{ }^{\bullet} \mathrm{OH}\right)$, superoxide anion radical $\left(\mathrm{O}_{2}^{\bullet}{ }^{-}\right)$, singlet oxygen $\left(\mathrm{O}_{2}^{\bullet}\right)$ 
and hydrogen peroxide $\left(\mathrm{H}_{2} \mathrm{O}_{2}\right)$ [38]. Contaminants' degradation in AOPs are stimulated either through radiolysis, sonolysis or photolysis. While radiolysis and sonolysis generate radicals in aqueous media without the use of chemical oxidants, photolysis may require the involvement of a catalyst or precursor. AOPs is comprised of a large range of technologies such as electrolysis, Fenton and photo-Fenton processes, wet air oxidation, ionization radiation, pulsed plasma, microwave, chemical oxidation processes, UV-based processes, supercritical water oxidation, and photocatalytic redox processes [39,40]. Also, hybrid AOPs involving the combination of two or more processes such electro-Fenton, and photoFenton processes have also been explored for the degradation of contaminants.

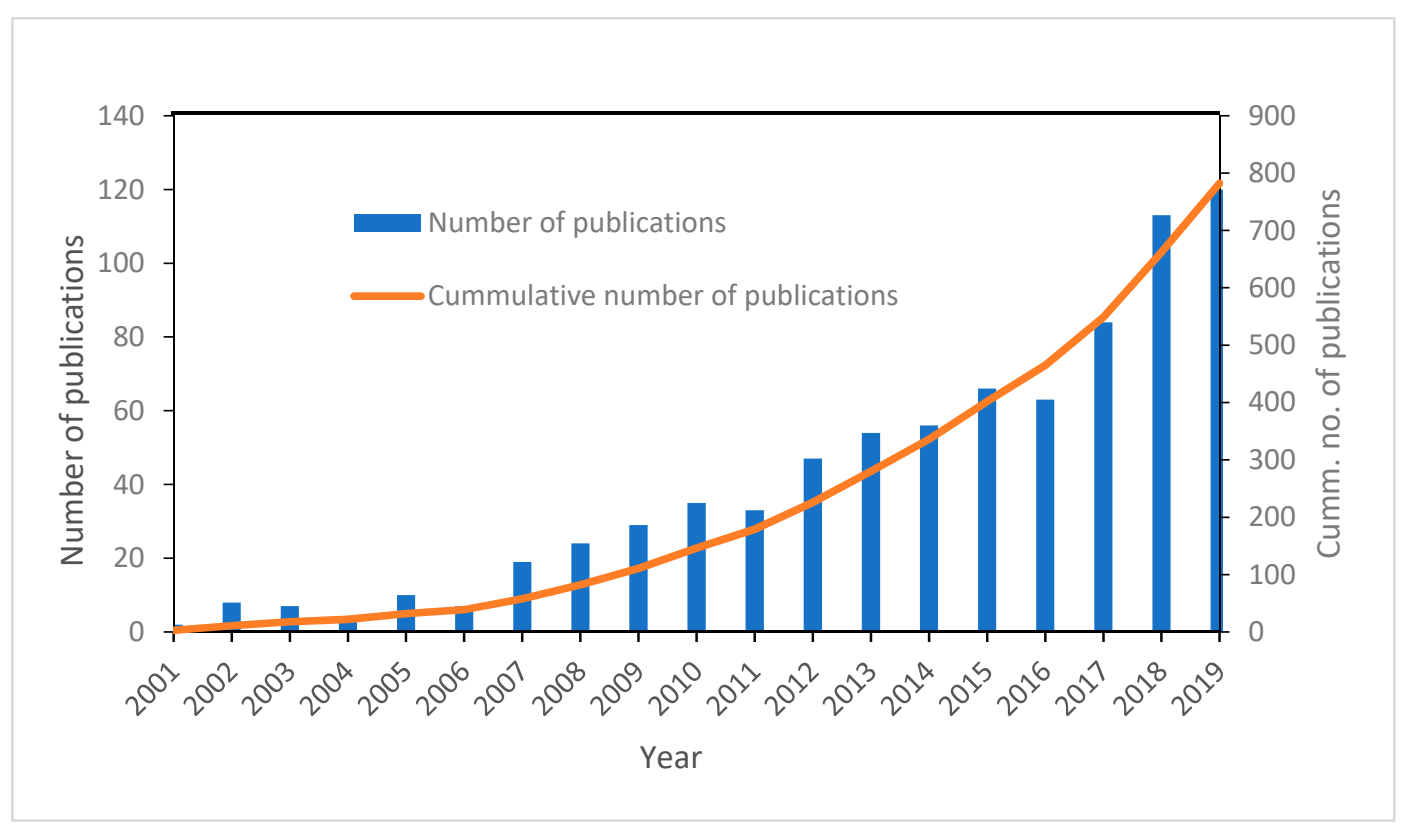

Figure 2. Timeline distribution of the annual and cumulative number of publications on the use of advanced oxidation processes for the degradation of pharmaceuticals.

Advanced oxidation processes have generated a lot of attention because of their rapid degradation rates for a wide range of chemicals, the ability to convert pollutants into simpler and biodegradable forms and the potential for complete mineralization of most pollutants. In addition, there is no need for secondary treatment of residual solids since no residual solid is generated and no regeneration is required to sustain process efficiency. Despite these advantages of AOPs, the process suffer from some disadvantages, which include: generation of unknown and undesirable transformation products; process may be capital intensive; water quality significantly impede the efficiency of the process and secondary processes for residual oxidant quenching may be required [41].

The use of heterogeneous photocatalytic process (HPPs), among other advanced oxidation processes, has gained much attention in the past three decades and has proven to be a suitable technique for the degradation and mineralization of different contaminants via a series of multi-step reactions to form low molecular weight end products, such as carboxylic acid, $\mathrm{CO}_{2}$ and $\mathrm{H}_{2} \mathrm{O}[42,43]$. The preference for HPPs is due mainly to their important, characteristic features which include: (i) ambient operating conditions, such as temperature and pressure (ii) potential mineralization of parent and transformation products without secondary pollution and (iii) economic feasibility and efficiency [44]. A broad class of semiconductor nanomaterials have been explored for HPP processes and could be broadly classified as metals, sulfides [45,46], oxides [47,48], nitrides [49,50], oxysulfides [51], oxyhalides [52,53] and oxynitrides [54,55]. The activity of semiconductors in light-induced redox process sensitization arise from the electronic structure of the metal 
atoms in chemical compounds. The electronic structure of these compounds is made up of filled valence band (VB) and an empty conduction band (CB) [43].

Supporting catalysts on suitable materials provides routes for the improvement of properties such as quantum efficiency, adsorption capacity, electronic band structure, stability, dispensability and the overall reaction rate of the process. Several class of materials currently being explored as catalyst-support include [56]: (i) carbon-based supports e.g., activated carbon, carbon nanotubes, graphite, graphene/graphene derivatives; (ii) ceramicbased supports e.g., silica, alumina, zirconia, zeolite, and silica carbide; (iii) metal-based supports e.g., chromium, platinum and cupper; and (iv) polymeric-based supports e.g., chitosan, polylactic acid, polyester and polyamides. Graphene or graphene derivatives such graphene oxide, reduced graphene oxide and doped graphene oxides are important class of support materials for catalytic degradation of contaminants in water. Incorporation of catalysts into graphene offer advantages such as high surface area and tensile strength, improved mobility and electron conductivity, lightweight, and stability [57].

There are several reviews on the degradation of pharmaceuticals in water [36,58-60], with focus mainly on adsorption and photocatalytic processes. In this present review, the degradation activity of graphene and graphene-based composites in AOPs such as direct catalytic degradation, electron-Fenton and chemical oxidation process, and sonocatalytic/sonophotocatalytic processes will be explored in addition to photocatalytic processes. Also, a comparative analysis of the identified processes will be carried out.

\section{Graphene/Graphene Derivatives}

Graphene is regarded as the strongest, thinnest and lightest compound known till date, and these properties are related to its structural features such as interlayer crosslinks arising either from covalent bonding between side atoms of different sheets or Van der Waals forces arising from interactions between carbon atoms of different layers of the graphene sheet. Also, intralayer forces, such as the $\mathrm{sp}^{2}$ carbon-carbon covalent bonds and crosslinks occurring at the graphene sheet edges contributes to the unique properties of graphene and its derivatives. Graphene-based materials are therefore outstanding materials for catalyst support in catalysis as they improve the stability and surface area of the catalyst, which is important in bringing the pollutants closer to the catalyst surface where catalytic activities occur.

Perfect graphene has a zero bandgap, and this makes pristine graphene a perfect conductor with high conductivity. The zero $\mathrm{E}_{\mathrm{g}}$ of graphene is due to the anti-bonding $\pi^{*}$ orbitals and bonding $\pi$ degenerate that meets at the Brillouin zone corners [61]. Doping of graphene leads to the formation of bandgap between the $\pi^{*}$ and $\pi$ orbital, thereby converting graphene into a semiconductor and creating more active sites for reactions. Large bandgap could be achieved by high dopant concentration, thus improving the electrical property of graphene [62,63].

Electron arrangement in the graphene lattice is dominated by the $\mathrm{s}$ and $\mathrm{p}$ orbitals. However, the low dispersibility, difficult recovery and ease of restacking are major drawbacks to its application. This informed the development of many strategies to modify it by incorporating several functional groups such as halogens, chalcogens, boron, nitrogen and phosphorus [64]. Complex functional groups such as aryl and alkyl hydrocarbons have also been reportedly incorporated [65]. The methods of incorporating functional groups into graphene are shown in Figure 3 . The most studied functionalized graphenes are graphene oxide (GO) and reduced graphene oxides (rGO), which are derivatives with poorly defined compositions that are strongly influenced by the synthesis method [64]. The abundance amount of oxygen functionalities on the GO surface, coupled with other properties such as structural defects, irregularity of heteroatoms makes them potential materials for specific applications. In graphene oxide, the electronic properties is strongly determined by its chemical structure [66]. Compared to graphene, GO is hydrophilic and an insulator by nature because of the presence of numerous surface hydroxyl $(-\mathrm{OH})$, keto $(\mathrm{C}=\mathrm{O})$, epoxy $(\mathrm{C}-\mathrm{O}-\mathrm{C})$ and carboxy $(-\mathrm{COOH})$ groups [67]. The formation of $\mathrm{C}-\mathrm{O}$ bond 
significantly induces the local distortion of graphene, altering the bonding character from planar $\mathrm{sp}^{2}$ to partial $\mathrm{sp}^{3}$ hybridization. By reducing GO, partial restoration of the intrinsic structural and electronic properties of graphene can be restored to produce rGO. However, the removal of oxygen-containing functionalities can lead to the rapid re-aggregation of rGO nanosheets into graphite [68]. Considering an arrangement of epoxy functional groups in fully oxidized graphene sheet and the effect of epoxy arrangement on electronic properties, a significant induction of bandgap of $0.529 \mathrm{eV}$ has been reported [69].

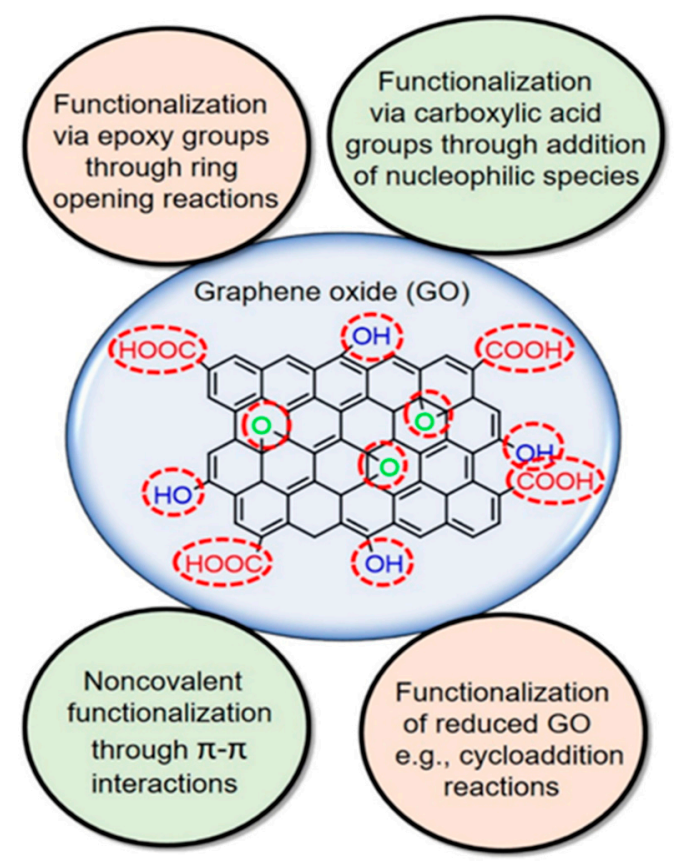

Figure 3. Different routes to graphene/graphene derivatives functionalization. Reproduced from Bilal, et al. [70]. Copyright (2020) Elsevier.

\subsection{Synthesis of Graphene Oxide and Reduced Graphene Oxide}

GO is widely employed in several applications because it is easy to synthesize, process and functionalize chemically. It is generally prepared either by the Brodie, Staudenmaier, Hummers, Tours or by modified forms of any of these methods. All the methods involve the oxidation of graphite to varying levels. The wet-chemical oxidative process used to convert graphite into GO involves four steps: (i) intercalation of graphite, (ii) oxidation, (iii) oxidized sheets exfoliation, and (iv) impurity removal [71-76]. The intercalation step involves the insertion of small molecules within the graphite layers. Alkali compounds such as $\mathrm{NaNO}_{3}$ and $\mathrm{KClO}_{3}$ are usually intercalated into the graphite layers, which is then subsequently oxidized by acids such as $\mathrm{HNO}_{3}, \mathrm{HCl}$ and $\mathrm{H}_{2} \mathrm{SO}_{4}$. The properties of the final product are influenced by several factors such as graphite's nature and source, nature and concentration of hydrogen peroxide, oxidant, water and sulfuric acid and physical parameters such as reaction time and temperature. The first reliable method for GO synthesis from graphite was reported in 1855 [77]. It involves the treatment of graphite with fuming $\mathrm{HNO}_{3}$ and $\mathrm{KClO}_{3}$. This method was improved on by using $\mathrm{H}_{2} \mathrm{SO}_{4}$ as additive and also the use of excess $\mathrm{HNO}_{3}$ [78]. It gave highly oxidized GO 'within a shorter period of time' compared to the Brodie method. The widely used Hummer's method involves the treatment of graphite with $\mathrm{NaNO}_{3}, \mathrm{KMnO}_{4}$ and $\mathrm{H}_{2} \mathrm{SO}_{4}$. Recently, the Tour's method as described by Marcano, et al. [79], introduced the use of $\mathrm{H}_{3} \mathrm{PO}_{4}$ as co-acids with $\mathrm{H}_{2} \mathrm{SO}_{4}$ and six equivalents of $\mathrm{KMnO}_{4}$ as oxidant.

Electrochemical stripping of graphite is another well explored technique for GO synthesis. This method is a safe, pollution-free, and efficient technique involving no chemical oxidant and achievable within hours or sometimes minutes. It also offers ease of manipulating GO properties such as defect density and degree of oxidation by tuning the 
electrical process $[80,81]$. The technique explores the conductivity of graphite to intercalate anions/molecules in the electrolyte under bias current or voltage. The GO is then obtained by ultrasonication of the graphite oxide formed through the oxidation of the graphite intercalation compound by oxygenated species produced by the electrolysis of water [82] The mechanism of formation of graphene oxide via the electrochemical stripping process is shown in Figure 4. The mechanism could either be anodic or cathodic based on the applied potential. In anodic process, electrons are withdrawn from the graphite electrode leading to the creation of positive charge, allowing for the intercalation of negatively charged ions like sulfate anions. In cathodic process, negative charges created at the graphite electrode attracts positively charge ions. Incorporation of these ions increase the interlayer spacing between the graphene sheets and enhance its exfoliation [83].

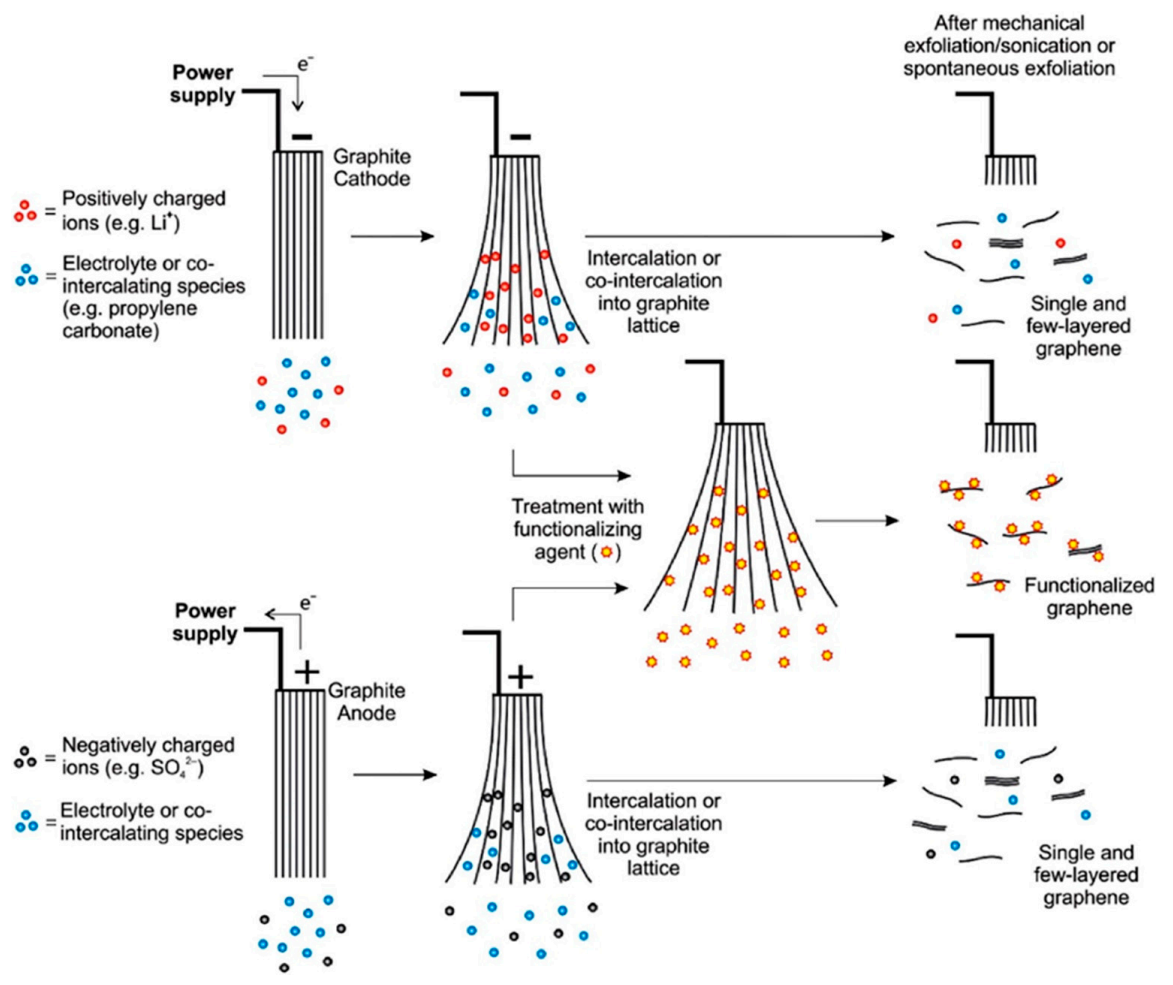

Figure 4. A schematic overview of mechanism of cathodic and anodic exfoliation. Functionalization of graphene may be achieved either during exfoliation by introducing functionalizing agent or after exfoliation. Reprinted with permission from Yu, et al. [83]. Copyright (2015) Elsevier.

The removal of oxygen functional groups from GO is a subject of continued research, with different methods such as thermal, photochemical, biological and chemical methods some of the already established routes as depicted in Figure 5 [84]. Each method produces rGO of varying properties such as morphology, dispersibility, conductivity and mechanical strength. The choice of the reduction method is influenced by factors such as $\mathrm{C} / \mathrm{O}$ ratio of end product, selectivity in removal of either $-\mathrm{OH},-\mathrm{COOH}$ or $\mathrm{C}-\mathrm{O}-\mathrm{C}$ functionalities, choice of reducing agent, surface defect reduction and improvement in chemical and physical properties [85]. The chemical method is the most explored routes to rGO and it involves treating GO suspension with reducing agents such as hydrazine [86-88], ascorbic acid [89-92], sodium borohydride [93-96] and sodium hypophosphite monohydrate $[97,98]$. In a report by Luo, et al. [99], the reduction of $\mathrm{GO}$ by $\mathrm{N}_{2} \mathrm{H}_{4} \bullet \mathrm{H}_{2} \mathrm{O}, \mathrm{NaBH}_{4}$, $\mathrm{NaOH}$, solvothermal, high-temperature, and a two-step method combining $\mathrm{NaBH}_{4}$ and high temperature was comparatively studied using four criteria: degree of reduction, level of defect repair, dispersibility, and electrical conductivity. The study showed that by combining two reduction processes, the properties of rGO could be greatly enhanced. 


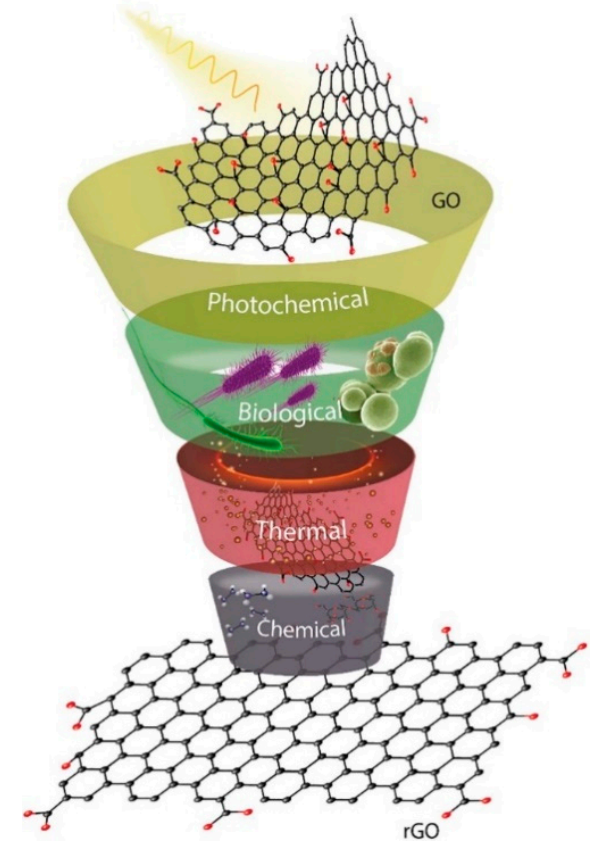

Figure 5. Routes to reduction of graphene oxide. Reprinted with permission from Agarwal and Zetterlund [100]. Copyright (2021) Elsevier.

Recently, the use of plant extracts as green reductants for rGO synthesis has been studied. The method involves the use of extracts from different plant parts such as seeds, roots, flowers and fruits. The reduction could be initiated by polyphenols (such as catechol and pyrogallol) or flavonoids (glucoside, diosmetin and apigenin) in the plant extracts. According to the mechanism proposed by Bhattacharya, et al. [101], shown in Figure 6, the carboxylic groups in GO reacts with reduced species in plant extracts to form esters by condensation reaction, which is further reduced by ring opening reaction. The hydroxyl groups are reduced by undergoing an initial condensation reaction, which is also followed by ring cleavage, while epoxy group reacts with polyhydroxy groups in extracts to form an intermediate that undergoes subsequent ring formation and cleavage.

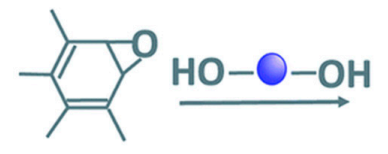

GO (Epoxide group)

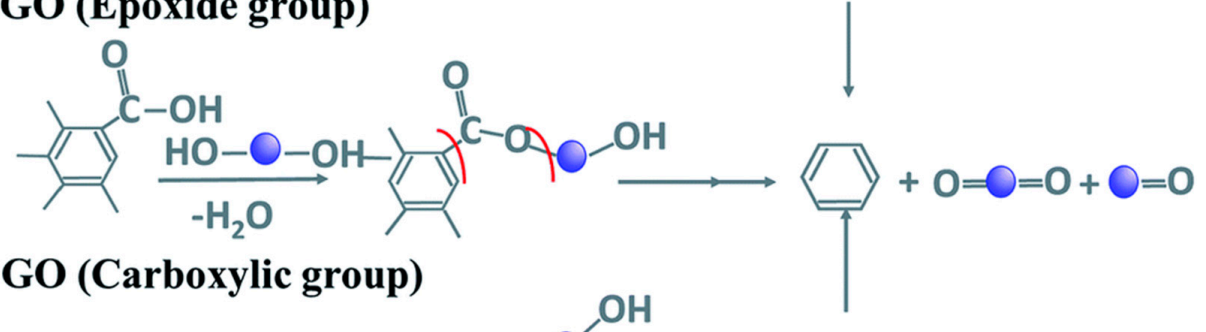<smiles>Cc1cc(O)c(C)c(C)c1CCCCCCCCCCCOO</smiles>

\section{GO (Hydroxyl group)}

Figure 6. Reduction of oxygen functionality in GO by plant extracts. Adapted with permission from Bhattacharya, et al. [101] under Creative Commons Attribution 4.0 International. 


\subsection{Composites of Graphene/Graphene Derivatives}

Increased utilization of graphene and its derivatives have motivated the exploration of different functionalization routes. Compositing of graphene with other nanomaterials take advantage of its superior properties to enhance catalytic activities. Graphene possess a two-dimensional carbon network with $\mathrm{sp}^{2}$ hybridization and it exhibits unique properties including high specific surface area, high intrinsic electron mobility and high thermal conductivity [102]. High degradation of pollutants could be achieved by hybridizing graphene with catalysts due to its effective electron conductivity and effective minimization of charge carrier's recombination via its acceptance of photogenerated electrons.

The improvement of catalytic activity by graphene and its derivatives is mainly due to their ability to extent light absorption range, absorptivity enhancement, enhanced surface area and improved charge separation and transport [103]. The compositing of a photocatalyst results in decreased $\mathrm{h}^{+} / \mathrm{e}^{-}$recombination and enhances the electron transfer rate, while also enhancing chemical species adsorption via $\pi-\pi$ interactions [104]. Generally, in graphene-based composites, graphene can either act as a support [105], dopant or a coating [106,107]. The three classes of composite could be prepared either via "ex situ" or "in situ" compositing as shown in Figure 7.
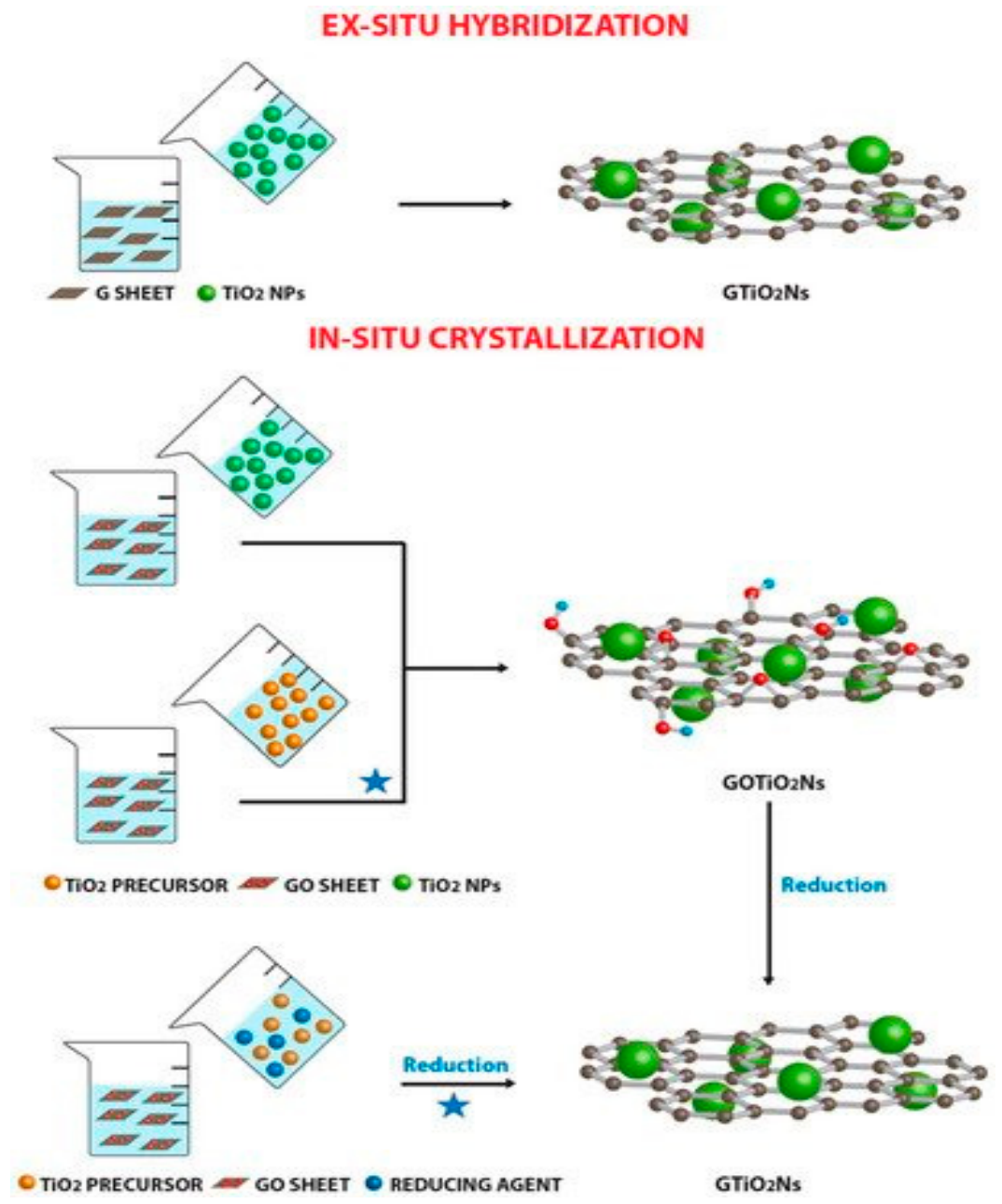

Figure 7. In-situ and Ex-situ compositing of metal salt with graphene and graphene derivatives. Reproduced with permission from Giovannetti, et al. [108] under Creative Commons Attribution 4.0 International.

Ex situ compositing process involves the mixing of nanoparticles with graphene dispersions. To enhance the process, the graphene sheets may be functionalized through 
covalent C-C coupling or non-covalent $\pi-\pi$ stacking reactions [109]. Ex situ compositing may sometimes result in low density and non-uniform distribution of the nanoparticles on the graphene. Several synthetic routes have been developed based on the ex situ process. AbdelDayem, et al. [110] reported the ex situ compositing of alumina with graphene oxide by mixing pre-prepared alumina with GO solution and refluxing the mixture at $80{ }^{\circ} \mathrm{C}$ for $8 \mathrm{~h}$. A two-phase method to the compositing of GO and CdS was reported by Gao, et al. [111]. In this method, synthesized GO and CdS were dispersed in water and toluene respectively. The two solutions were then mixed together and stirred continuously for $24 \mathrm{~h}$, followed by washing and drying. The interaction between the GO functional groups and CdS led to the distribution of the CdS on the GO surface and the aggregation of the $\mathrm{CdS}$ particles was minimized by the process. The synthesis of $\mathrm{TiO}_{2} @ \mathrm{rGO}$ through mechanochemical synthesis involving the grinding of $\mathrm{TiO}_{2}$ nanoparticles and $\mathrm{rGO}$ was also reported by Deng, et al. [112].

The in-situ method is the most explored for graphene/nanoparticle composites and it involves direct reaction of GO/rGO sheets and nanoparticles' precursors in solution. The growth of nanoparticles on the surface of GO/rGO have been explored widely through solvothermal and/or hydrothermal techniques. It has been explored frequently in the synthesis of GO/rGO-metal oxide/sulphide nanocomposites. In the in-situ method, nanoparticle nucleation and growth occur on the $\mathrm{GO} / \mathrm{rGO}$ surface under high-temperature and pressure, with the hydroxyl and carboxyl functional groups acting as nucleation sites for nanoparticles growth via metal-O-C bond formation [113-115]. A microwave assisted reduction synthetic method via a mixture of $\mathrm{PdCl}_{2}, \mathrm{RuCl}_{3}$ and GO, was employed for the synthesis of bimetallic-graphene composite. Reduction of the metal salts to metallic state was achieved with $\mathrm{NaBH}_{4}$, which was enhanced by holding the mixture in a microwave oven [116]. A method involving the mixture of $\mathrm{GO} / \mathrm{rGO}$ precursor and nanoparticle precursors was described by Anand, et al. [117] for the synthesis of $\mathrm{rGO} / \mathrm{Bi}_{2} \mathrm{Al}_{4} \mathrm{O}_{9}$. In the synthesis $\left[\mathrm{Bi}\left(\mathrm{NO}_{3}\right) \bullet 5 \mathrm{H}_{2} \mathrm{O}\right]$ and $\mathrm{AlNO}_{3} \bullet 9 \mathrm{H}_{2} \mathrm{O}$ were dissolved into the graphene oxide synthesis set-up. The mixture was then stirred for $30 \mathrm{~min}$ and further sonicated for $5 \mathrm{~min}$. The process of stirring and sonicating was repeated for $4 \mathrm{~h}$, and the reaction was quenched afterwards. GO reduction to $\mathrm{rGO}$ was achieved by adding $10 \%$ ascorbic acid solution to the reaction system and heating at $95{ }^{\circ} \mathrm{C}$ for $1 \mathrm{~h}$. Cao, et al. [118] reported the combination of precursor mixing and annealing for the in-situ synthesis of $\mathrm{ZnO} / \mathrm{rGO}$. In this synthesis route, $\mathrm{ZnO}$ powder was firstly mixed with $\mathrm{GO}$ solution and the mixture stirred vigorously for $3 \mathrm{~h}$. The mixture was further kept at room temperature for $3 \mathrm{~h}$ and the product was collected by centrifugation, then dried at $60^{\circ} \mathrm{C}$ for $12 \mathrm{~h}$. The product was annealed for $2 \mathrm{~h}$ at $350{ }^{\circ} \mathrm{C}$ at a heating rate of $2{ }^{\circ} \mathrm{C} / \mathrm{min}$ to obtain the $\mathrm{ZnO} / \mathrm{rGO}$.

Electrochemical exfoliation method is another simple and one-step ex-situ technique used in preparing GO/rGO-composites. Ansari and Payami [119] reported the synthesis of magnetic graphene- $\mathrm{Fe}_{2} \mathrm{O}_{3}$ nanocomposite using this method. The electrolytic cell was made with graphite foil anode and iron plate as cathode, and applying a voltage of $10 \mathrm{~V}$ $\mathrm{DC}$ for $3 \mathrm{~h}$. In a study to evaluate the effect of synthesis method on the properties of $\mathrm{GO} / \mathrm{rGO}$-composite, Aquino, et al. [120] reported the synthesis of $\mathrm{GO} / \mathrm{WO}_{3} \mathrm{NW} / \mathrm{PANI}$ through chemical and electrochemical routes. It was reported that the electrochemical process resulted in a composite with disorganized structure, which however, increased the doping level in the polymer chain, enhanced porosity and also permitted higher synergistic effect among the components of the composites, when compared to the nanocomposites prepared via the chemical route.

The growth of nanoparticles on GO/rGO sheets is influenced by the amount of functional group present on the sheet [121]. So, compared to rGO, GO can facilitate the growth of nanoparticles leading to higher density and smaller nanoparticle size [122]. Therefore, to overcome low particle loading and poor solubility of rGO, surfactant molecules or polymers are employed in composite synthesis. The synthesis of $\mathrm{Pd}-\mathrm{CuO} / \mathrm{rGO}$ and $\mathrm{Au}-\mathrm{CuO} / \mathrm{rGO}$ via an ionic liquid-assisted approach was reported by Alhumaimess, et al. [123]. The 
addition of little amount of the ionic liquid 1-butyl-3methyl imidazolium tetrafluoroborate resulted in uniformly dispersed nanoparticles, with simultaneous reduction of GO.

Graphene doped with heteroatoms such as nitrogen (N), sulphur (S), boron (B) have also been explored in synthesis of composites with semiconductors. Ex-situ synthesis of doped-GO/rGO-composite such as N-graphene, and B-graphene have also been reported. Liu, et al. [124] reported the solvothermal synthesis of $\mathrm{NG} / \mathrm{TiO}_{2}$ by mixing $\mathrm{N}$-graphene oxide and $\mathrm{TiO}_{2}$ in a Teflon-lined reactor. The synthesis of $\mathrm{Co}_{3} \mathrm{Sn}_{2} @ \mathrm{Co}-\mathrm{NG}$ was also reported by Mahmood, et al. [125] via the in-situ approach.

\section{Catalytic Activity of Graphene-Based Composites in the Degradation of Pharmaceuticals}

The enhanced catalytic properties of graphene-supported composites have been studied in different technologies for the degradation of pharmaceuticals. While the photocatalytic process is the most explored technique, other degradation processes such as direct degradation, chemical oxidation, electrochemical and sonochemical/sono-photochemical processes have also been identified; thus, affirming the versatility of this composites as catalysts for pharmaceutical degradation.

\subsection{Direct Degradation Processes}

Although, most catalytic application of graphene composites in degradation of pollutants have focused on processes involving the addition of chemicals such as persulfate or light energy, few processes have been explored without these complementary components. Saroyan, et al. [126] reported the degradation of bisphenol-A by graphite oxide composited with mixed oxidation state manganese oxide. The improved catalytic activity was correlated with the improved adsorption of bisphenol-A unto the composite, which brought the BPA into close proximity with the $\mathrm{Mn}_{3} \mathrm{O}_{4}$. The activity of the composite was optimal at $\mathrm{pH}$ of 3, reaching a degradation efficiency of $93 \%$. The degradation of tetracycline by $\mathrm{MnO}_{2}$ supported on a three-dimensional graphene was also reported by Song, et al. [127] with efficiency of up to $91 \%$ and rate constant of $0.136 \mu \mathrm{M} / \mathrm{min}$.

\subsection{Chemical Oxidation Processes}

Peroxymonosulfate (PMS)- or persulfate (PS)-based oxidation processes are effective routes to the degradation of recalcitrant and refractory pollutants because of their great oxidation capacity and high selectivity. The activation of persulfate by processes such as heating, ultrasound, UV light, transition metal ion and alkaline conditions leads to the generation of $\mathrm{SO}_{4}^{-}{ }^{-}$. Due to the recent interest in heterogeneous catalysis, the use of solid catalysts has gained much focus because of their excellent catalytic activity, stability and ease of separation. Solid catalysts based on magnetic spinel-type ferrite materials $\left(\mathrm{MFe}_{2} \mathrm{O}_{4}\right.$, $\mathrm{M}=\mathrm{Co}, \mathrm{Fe}, \mathrm{Ni}, \mathrm{Zn}$, and $\mathrm{Cu}$ ) can act as heterogeneous Fenton-like catalysts for the activation of PS. Recent studies have shown that the compositing of these catalysts with GO/rGO could enhance the PS activation activity of these heterogeneous catalysts.

The primary mechanism of persulfate activation by carbonaceous materials as shown in Figure 8 is based on the one-electron transfer route (Equation (1)) $[128,129]$. The generation of ${ }^{\bullet} \mathrm{OH}$ is also possible via the reaction expressed in Equation (2). In both reactions, radical species generated are responsible for the degradation of organic compounds. Nonradical routes involving transfer of electrons from organic compounds to persulfate and/or singlet oxygen generation could also occur. The ability of doped graphene to effectively activate PS was reported by Chen and Carroll [130] in which 99.9\% degradation of sulfamethoxazole was achieved by N-doped graphene. The enhanced activity was attributed to the increased nitrogen groups such as pyridinic- $\mathrm{N}$ and quaternary- $\mathrm{N}$, which acts as adsorption sites and source of free-flowing $\pi$-electrons for PS activation.

$$
\begin{gathered}
\mathrm{S}_{2} \mathrm{O}_{8}^{2-}+\mathrm{e}^{-} \rightarrow \mathrm{SO}_{4}^{\bullet-}+\mathrm{SO}_{4}^{2-} \\
\mathrm{SO}_{4}^{\bullet-}+\mathrm{OH}^{-} \rightarrow \mathrm{SO}_{4}^{2-}+{ }^{\bullet} \mathrm{OH}
\end{gathered}
$$




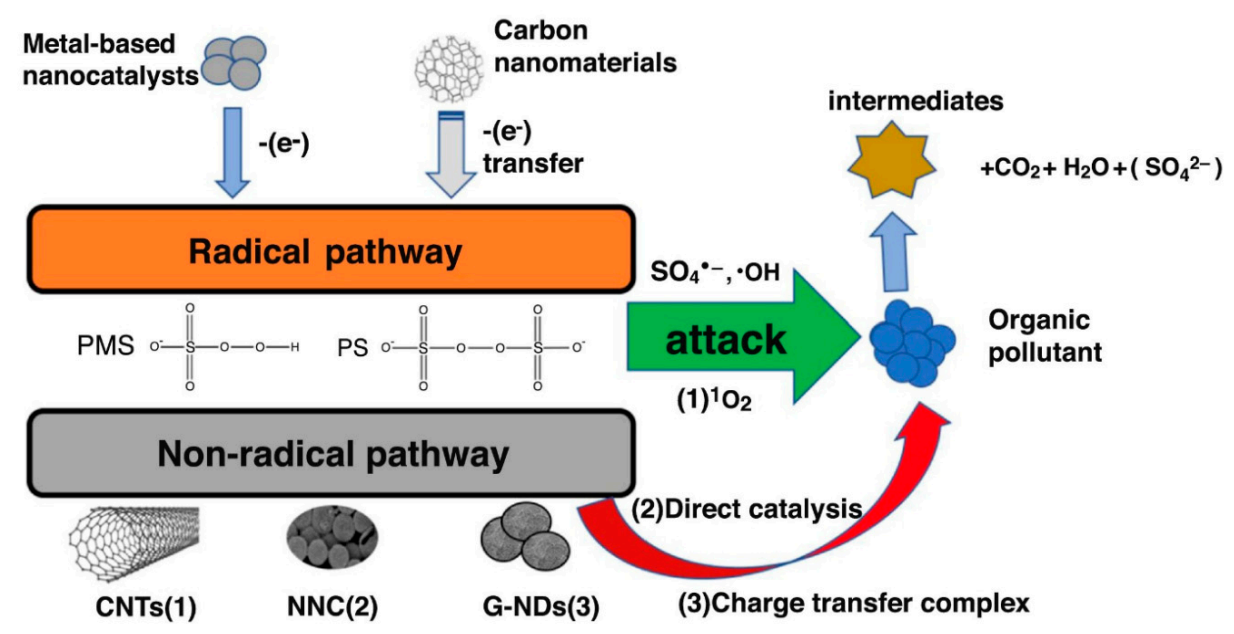

Figure 8. Mechanism of persulfate activation by metal-based catalysts and carbonaceous materials. Reproduced with permission from Xiao, et al. [128]. Copyright (2018) Elsevier.

The degradation of methylparaben by $\mathrm{CuFe}_{2} \mathrm{O}_{4}$-rGO in the presence of PS showed a degradation efficiency of $95 \%$ with mineralization efficiency of $73 \%$ compared to 38 and $20 \%$ degradation and mineralization efficiencies respectively observed for $\mathrm{CuFe}_{2} \mathrm{O}_{4}$. The reaction rate constant for the rGO supported catalyst was almost 7-fold the value observed for bare $\mathrm{CuFe}_{2} \mathrm{O}_{4}$. The improved activity of the supported catalyst was attributed to the direct activation of $\mathrm{PS}$ via electron transfer reactions involving the $-\mathrm{COOH}$ and $\mathrm{O}-\mathrm{C}=\mathrm{O}$

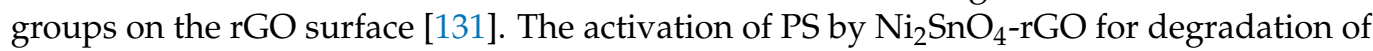
bisphenol A was reported by Jiang et al. [132]. Compositing of the catalyst with rGO reportedly increased the degradation efficiency of the process by $32 \%$. This was attributed to the ability of rGO to prevent the aggregation of the $\mathrm{Ni}_{2} \mathrm{SnO}_{4}$ nanoparticles; thus, increasing the active sites of the catalyst.

Vieira et al. [133] reported the synthesis of a membrane based on carbon-polymer nanocomposite obtained by compositing nitrogen-doped reduced graphene oxide with poly(vinylidene fluoride) (rGO-M-PVDF). The composite was explored for PS activation in the degradation of ofloxacin (OFX), ciprofloxacin (CIP) and enrofloxacin (EFX), with degradation efficiencies of 54,77 and $91 \%$ respectively. The degradation pathway was observed to be by both radical and non-radical oxidation routes. Evaluation of the surface group present in the spent membrane showed that a loss in the N-pyridinic group was observed, while the $\mathrm{N}$-pyrrolic and $\mathrm{N}$-quaternary group remained unchanged in the membrane. This confirmed that the $\mathrm{N}$-pyridinic group accounts for the catalytic activity of the membrane. Also, the non-radical process occurred via the singlet oxygen generated in the reaction system. The degradation of bisphenol, phenol, acetaminophen and sulfamethoxazole by visible-light activated persulfate using $\mathrm{Ti}^{3+}$ self-doped $\mathrm{TiO}_{2} / \mathrm{GO}$ composite was reported by Yang, et al. [134]. The efficiency of the process reached $99 \%$ after just $12 \mathrm{~min}$ for bisphenol degradation, implying the enhanced activation of persulfate by the $\mathrm{TiO}_{2-\mathrm{x}} / \mathrm{rGO}$ composite. As shown in Figure 9A,B, the synergy between the self-doped $\mathrm{TiO}_{2}$ and $\mathrm{rGO}$ was important for enhanced degradation efficiency and high reaction rate. The process showed higher degradation and mineralization efficiency towards bisphenol and acetaminophen, with almost complete degradation achieved as shown in Figure 9C,D. Studies carried out on the degradation process showed that persulfate was activated by electrons generated by the photocatalyst, leading to the generation of ${ }^{\bullet} \mathrm{OH}$ and $\mathrm{SO}_{4}^{\bullet-}$, which attacks the contaminants as shown in Figure 9F. Photoluminescence spectra of the composite (Figure 9E) showed a significant reduction in $\mathrm{e}-/ \mathrm{h}+$ recombination, which accounts for high efficiency of the process. 

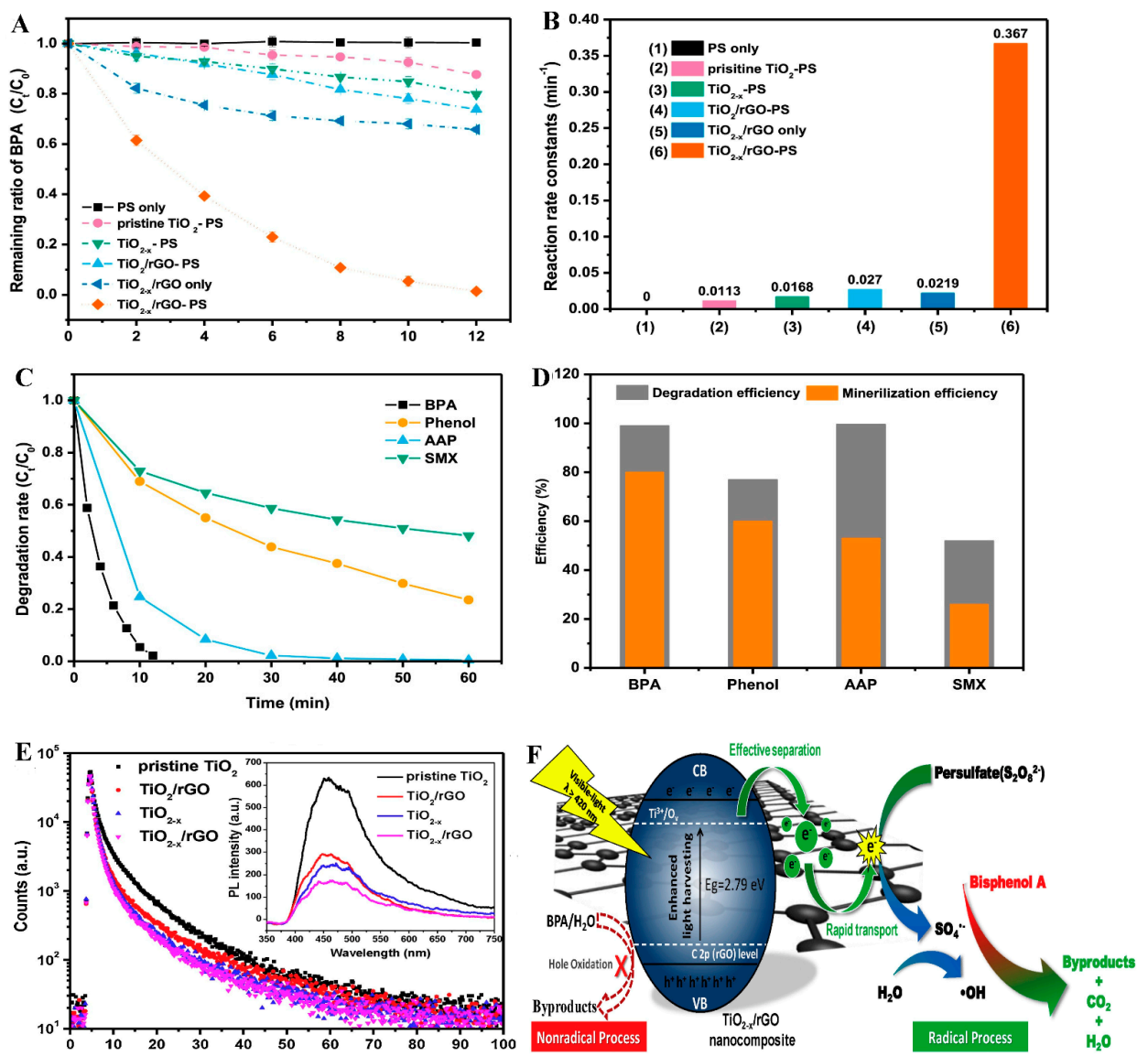

Figure 9. Degradation of bisphenol, phenol, acetaminophen and sulfamethoxazole by $\mathrm{TiO}_{2-\mathrm{x}} / \mathrm{rGO}$ (A) degradation efficiency of bisphenol by PS only, pristine $\mathrm{TiO}_{2}+\mathrm{PS}, \mathrm{TiO}_{2-\mathrm{x}}+\mathrm{PS}, \mathrm{TiO}_{2-\mathrm{x}}+\mathrm{PS}, \mathrm{TiO}_{2-\mathrm{x}} / \mathrm{rGO}, \mathrm{TiO}_{2-\mathrm{x}} / \mathrm{rGO}+\mathrm{PS}(\mathbf{B}) \mathrm{kinetic}$ of degradation of bisphenol by PS only, pristine $\mathrm{TiO}_{2}+\mathrm{PS}, \mathrm{TiO}_{2-x}+\mathrm{PS}, \mathrm{TiO}_{2-x}+\mathrm{PS}, \mathrm{TiO}_{2-x} / \mathrm{rGO}, \mathrm{TiO}_{2-x} / \mathrm{rGO}+\mathrm{PS}(\mathrm{C})$ Efficiency of $\mathrm{TiO}_{2-\mathrm{x}} / \mathrm{rGO}+\mathrm{PS}$ for bisphenol, phenol, acetaminophen and sulfamethoxazole degradation (D) degradation and mineralization of $\mathrm{TiO}_{2-x} / \mathrm{rGO}+\mathrm{PS}$ for bisphenol, phenol, acetaminophen and sulfamethoxazole degradation (E) Time resolved PL spectra of $\mathrm{TiO}_{2-\mathrm{x}} / \mathrm{rGO}$ (inset) steady state PL spectra. (F) Mechanism of action of $\mathrm{TiO}_{2-\mathrm{x}} / \mathrm{rGO}$ for bisphenol degradation. Adapted with permission from Yang, et al. [134].

The mechanism of PMS activation by $\mathrm{rGO}-\mathrm{CoFe}_{2} \mathrm{O}_{4}$ for ofloxacin and cefazolin degradation was reported by Fan et al. [135]. The study showed that while sulfate radicals were the major active species in ofloxacin degradation, non-radical oxidation by PMS direct two-electron transfer was prevalent in cefazolin degradation. The difference in degradation routes was attributed to the difference in the nucleophilicity and electrophilicity of different sites on the antibiotics. The activation of PMS was achieved via three different redox reactions between $\mathrm{Co}(\mathrm{II}) / \mathrm{Co}(\mathrm{III}), \mathrm{Fe}(\mathrm{II}) / \mathrm{Fe}(\mathrm{III})$ and lattice oxygen $/ \mathrm{O}_{2}$ from $\mathrm{rGO}-\mathrm{CoFe}_{2} \mathrm{O}_{4}$. Complete degradation of the pharmaceuticals was achieved under 30 min using $0.1 \mathrm{~g} / \mathrm{L}$ catalyst concentration and 1 mM PMS.

Other graphene-based composites employed for the activation of persulfate in pharmaceutical degradation are presented in Table 2. The suitability of this process for pharmaceutical degradation could be observed as high degradation efficiencies and reaction rates were reported for the process. Most of the reported studies were carried out under acidic conditions, thus suggesting the preference for acidic conditions for optimal activity. It is observed that significant degradation of pharmaceuticals could be achieved within relatively short reaction times, which is an important factor for adaptation in treating large volume of wastewater in treatment plants. The presence of chalcogens such as $\mathrm{N}, \mathrm{O}$ and $S$ on the composite played significant role in persulfate activation and a corresponding increase in the activity of the composites. 
Table 2. Chemical oxidation processes based on graphene-based composites for degradation of pharmaceuticals.

\begin{tabular}{|c|c|c|c|c|c|c|}
\hline Catalyst & Pharmaceutical & Process Parameter & Degradation Efficiency & Reaction Rate & Process Overview & Ref \\
\hline graphene & $\begin{array}{c}\text { Diclofenac, } \\
\text { Norfloxacin, } \\
\text { Tetracycline, } \\
\text { sulfamethoxazole }\end{array}$ & $\begin{array}{c}\mid \text { Cat }|=100 \mathrm{mg} / \mathrm{mL} ;| \mathrm{Pol} \mid= \\
5 \mathrm{mg} / \mathrm{L} ;|\mathrm{PMS}| 0.5 \mathrm{mM} \\
\mathrm{pH}=4.0 ; \text { Time }=120 \mathrm{~min}\end{array}$ & $\begin{array}{c}84 \\
100 \\
100 \\
100\end{array}$ & $5.92 \times 10^{3} \mathrm{~min}^{-1}$ & $\begin{array}{l}\text { The effect of adsorption on removal of } \\
\text { pharmaceuticals was studies. It was } \\
\text { observed that degradation was influenced } \\
\text { by the adsorption capacity of graphene for } \\
\text { the pharmaceuticals }\end{array}$ & [136] \\
\hline $\mathrm{CoFe}_{2} \mathrm{O}_{4}-\mathrm{GO}$ & Norfloxacin & $\begin{array}{c}\mid \text { Cat }|=0.3 \mathrm{~g} / \mathrm{L} ;| \mathrm{Pol} \mid=15 \mu \mathrm{M} \\
|\mathrm{PMS}|=0.5 \mathrm{mM} ; \mathrm{pH}=7 \\
\text { Time }=20 \mathrm{~min}\end{array}$ & 100 & $0.29 \mathrm{~min}^{-1}$ & $\begin{array}{l}\text { The study reported that the compositing of } \\
\mathrm{CoFe}_{2} \mathrm{O}_{4} \text { with graphen oxide (GO) altered } \\
\text { the mechanism of norfloxacin which was } \\
\text { dominated by non-radical processes, unlike } \\
\text { in degradation involving pristine } \mathrm{CoFe}_{2} \mathrm{O}_{4} \\
\text { which was dominated by radical processes }\end{array}$ & [137] \\
\hline $\mathrm{TiO}_{2} / \mathrm{rGO} / \mathrm{PS}$ & Antipyrine & $\begin{array}{c}\mid \text { Cat }|=150 \mathrm{mg} / \mathrm{mL} ;| \mathrm{Pol} \mid= \\
5 \mathrm{mg} / \mathrm{L} ;|\mathrm{PMS}|=300 \mathrm{mg} / \mathrm{L} \mathrm{mM} \\
\mathrm{pH}=7.0 ; \text { Time }=45 \mathrm{~min}\end{array}$ & 100 & - & $\begin{array}{l}\text { The reaction between the conduction band } \\
\text { electrons and persulfate reduced the } \\
\text { recombination of the generated e- } / \mathrm{h}+\text { pairs } \\
\text { leading to enhanced degradation of } \\
\text { pollutant }\end{array}$ & [138] \\
\hline $\begin{array}{c}\mathrm{rGO}- \\
\mathrm{Ag}^{0} / \mathrm{Fe}_{3} \mathrm{O}_{4}\end{array}$ & $\begin{array}{l}\text { Phenol, } \\
\text { acetaminophen, } \\
\text { ibuprofen, } \\
\text { naproxen, } \\
\text { bisphenol }\end{array}$ & $\begin{array}{c}\mid \text { Cat }|=1 \mathrm{mg} / \mathrm{mL} ;| \mathrm{Pol} \mid=10 \mu \mathrm{M} ; \\
|\mathrm{PDS}|=1 \mathrm{mM} \\
\mathrm{pH}=7.0 ; \text { Time }=360 \mathrm{~min}\end{array}$ & $\begin{array}{c}50 \\
99 \\
>90 \\
<50 \\
<50\end{array}$ & $\begin{array}{l}0.46 \mathrm{~h}^{-1} \\
6.19 \mathrm{~h}^{-1} \\
1.93 \mathrm{~h}^{-1} \\
0.90 \mathrm{~h}^{-1} \\
0.57 \mathrm{~h}^{-1}\end{array}$ & $\begin{array}{l}\text { Under acidic condition ( } \mathrm{pH} 4 \text { ) the catalyst } \\
\text { showed low substrate-dependent activity, } \\
\text { however under neutral/basic conditions } \\
\text { (pH } 7 \text { and 10), the activity of the catalyst } \\
\text { was substrate specific. }\end{array}$ & [139] \\
\hline Go-MCM-Fe & $\begin{array}{l}\text { Levofloxacin } \\
\text { hydrochloride }\end{array}$ & $\begin{array}{c}\text { Cat }|=50 \mathrm{mg} / \mathrm{mL} ;| \mathrm{Pol} \mid= \\
100 \mathrm{mg} / \mathrm{L} ;\left|\mathrm{S}_{2} \mathrm{O}_{8}^{2-}\right|=0.02 \mathrm{~g} \\
\mathrm{pH}=4.3 ; \text { Time }=60 \mathrm{~min}\end{array}$ & 97.1 & $0.354 \mathrm{~min}^{-1}$ & $\begin{array}{l}\text { The solvothermal process was used in } \\
\text { compositing MCM- } 41, \mathrm{GO} \text { and iron. The } \\
\text { incorporation of GO resulted in increased } \\
\text { strength of the composite. Also, increasing } \\
\text { the quantities of GO and iron lead to } \\
\text { increased catalytic activity. Quenching } \\
\text { experiments confirmed }{ }^{\circ} \mathrm{OH} \text { and } \mathrm{SO}_{4}^{\circ-} \\
\text { radicals as the main } \mathrm{ROS} \text { generated in the } \\
\text { system }\end{array}$ & [140] \\
\hline $\begin{array}{c}\mathrm{N}- \\
\mathrm{rGO} / \mathrm{Fe}_{3} \mathrm{O}_{4} / \mathrm{PS}\end{array}$ & Norfloxacin & $\begin{array}{c}\text { Cat }|=100 \mathrm{mg} / \mathrm{mL} ;| \mathrm{Pol} \mid= \\
20 \mathrm{mg} / \mathrm{L} ;\left|\mathrm{S}_{2} \mathrm{O}_{8}^{2-}\right|=10 \mathrm{mM} \\
\mathrm{pH}=7.0 ; \text { Time }=210 \mathrm{~min}\end{array}$ & 100 & $0.0047 \mathrm{~min}^{-1}$ & $\begin{array}{l}\text { The prepared composite showed high } \\
\text { adsorption capacity for norfloxacin, which } \\
\text { was degraded by }{ }^{\bullet} \mathrm{OH} \text { and } \mathrm{SO}_{4}^{\bullet-} \text { generated } \\
\text { by the activation of persulfate }\end{array}$ & [141] \\
\hline
\end{tabular}


Table 2. Cont.

\begin{tabular}{|c|c|c|c|c|c|c|}
\hline Catalyst & Pharmaceutical & Process Parameter & Degradation Efficiency & Reaction Rate & Process Overview & Ref \\
\hline Ni@NPG & Sulfachloropyridazine & $\begin{array}{c}\text { Cat }|=0.05 \mathrm{~g} / \mathrm{mL} ;| \mathrm{Pol} \mid= \\
20 \mathrm{mg} / \mathrm{L} ;\left|\mathrm{S}_{2} \mathrm{O}_{8}^{2-}\right|=2 \mathrm{~g} / \mathrm{L} ; \\
\text { Time }=30 \mathrm{~min}\end{array}$ & 100 & $0.46 \min ^{-1}$ & $\begin{array}{l}\text { The synthesized N doped graphene } \\
\text { encapsulated Ni composite benefited from } \\
\text { the 3-dimensional structure of the } \\
\text { composite, and the synergistic effect of } \\
\text { N-doping and nickel encapsulation. The } \\
\text { degradation mechanism revealed a } \\
\text { dominant non-radical pathway. }\end{array}$ & [142] \\
\hline GO-TiO 2 & Diclofenac & $\begin{array}{c}\text { Cat }|=0.1 \mathrm{~g} / \mathrm{L} ;| \mathrm{Pol} \mid=20 \mathrm{mg} / \mathrm{L} ; \\
\left|\mathrm{S}_{2} \mathrm{O}_{8}^{2-}\right|=10 \mathrm{~g} / \mathrm{L} \\
\mathrm{pH}=5.4 ; \text { Time }=14 \mathrm{~min}\end{array}$ & 93.06 & - & $\begin{array}{l}\text { The degradation of diclofenac was studied } \\
\text { using composite centered design. The most } \\
\text { significant variable that influences the } \\
\text { degradation efficiency was } \mathrm{pH} \text { and the } \\
\text { catalyst concentration }\end{array}$ & [143] \\
\hline
\end{tabular}




\subsection{Photocatalysis}

Photocatalysis involves the use of semiconducting materials such as oxides, sulphides and nitrides, that have the capacity to absorb light energy and generate reactive oxygen species (ROS). The generated $\mathrm{ROS}$ such as ${ }^{\bullet} \mathrm{OH}$ and $\mathrm{O}_{2}^{\bullet-}$ are responsible for the degradation of organic pollutants via a redox process [144]. For ROS generation, light of equal or higher energy compared to the band gap of the semiconductor irradiates the semiconductor surface, leading to the excitation of electrons from the valence band into the conduction band and holes are left in the conduction band. This is referred to as electron-hole $\left(\mathrm{e}^{-} / \mathrm{h}^{+}\right)$ pairs generation. The electronhole pairs react with oxygenated species such as water and air on the surface of the catalyst to generate ROS. The electron is responsible for the formation of $\mathrm{O}_{2}^{-}$- via dissolved oxygen reduction, while oxidation of water by hole leads to the formation of hydrogen gas and ${ }^{\bullet} \mathrm{OH}$. The $\mathrm{O}_{2}^{\bullet}{ }^{-}$could subsequently produce $\mathrm{H}_{2} \mathrm{O}_{2}$ by reacting with $\mathrm{H}_{2} \mathrm{O}$ leading to more ${ }^{\bullet} \mathrm{OH}$ production.

\subsubsection{Metal Oxide-Based Graphene Composite Photocatalysts}

Several metal oxide-graphene composites have been explored as photocatalysts for degradation of pharmaceuticals. Bhatia et al. [6] reported the degradation of $25 \mathrm{ppm}$ of atenolol using a GO supported $\mathrm{TiO}_{2}$, which achieved $72 \%$ degradation under a simulated solar light irradiation for $1 \mathrm{~h}$. Using Degussa P25 as catalyst, a degradation efficiency of $56 \%$ was achieved by the process. Evaluation of the effect of catalyst concentration on the system shows that while the degradation of the contaminant increased with increase in catalyst's concentration when Degussa P25 was used, a reduction in photocatalytic activity was observed for the GO supported photocatalyst. This was attributed to the reduction in light penetration into the system as a result of the shielding effect of GO on the catalyst particles. In another study to optimize the degradation process for atenolol using a graphene- $\mathrm{TiO}_{2}$ composite, Bhatia, et al. [145], studied a four-factor three-level Box-Benkhen design to determine the optimal condition for the process. The photocatalyst concentration, $\mathrm{pH}$, atenolol concentration and light intensity at levels of 10-20\%, 4-9, 10-30 mg/L and $60-260 \mathrm{~W} / \mathrm{m}^{2}$ respectively were studied. The study showed that the optimum rate constant for the process was $0.667 \mathrm{~min}^{-1}$, which was achieved by catalyst concentration of $10 \%$, $\mathrm{pH}$ of 6.5 , light intensity of $160 \mathrm{~W} / \mathrm{m}^{2}$ and atenolol concentration of $30 \mathrm{mg} / \mathrm{L}$. The effect of the presence of $\mathrm{H}_{2} \mathrm{O}_{2}$ on the photocatalytic degradation of acetaminophen (ACT) by a $\mathrm{TiO}_{2} @ \mathrm{rGO}$ composite, showed that the degradation and mineralization efficiency of the catalyst could be enhanced by a multiple of 4 and 3 respectively by the introduction of $\mathrm{H}_{2} \mathrm{O}_{2}$ into the system [146]. Further study on the effect of rGO on the photocatalytic process showed the catalytic activity was maximum at 3\% rGO concentration, with further increase resulting in inhibition of catalytic activity.

Heterojunctions based on graphene-metal oxide composite semiconductors have also been reported as photocatalysts for pharmaceutical degradation. The degradation of three pharmaceuticals: bisphenol-A (BPA), ibuprofen (IBP) and flurbiprofen (FBP) by graphene oxide based $\mathrm{TiO}_{2}-\mathrm{ZnO}$ heterojunction was reported by Bilgin Simsek, et al. [147]. The study showed that a degradation efficiency of $99.7,98.5$ and $98.1 \%$ of BPA, IBP and FBP was achieved by subjecting $10 \mathrm{mg} / \mathrm{L}$ of the pollutant solution to light irradiation at $\mathrm{pH}$ of 6.0 for $2 \mathrm{~h}$ under UV irradiation. The enhanced activity of the composite was attributed to the electron withdrawing properties of graphene. When other combinations between the three components of the catalyst were considered, the catalytic activity of the catalysts was reported to be in the order $\mathrm{RGO} / \mathrm{TiO}_{2} / \mathrm{ZnO}>\mathrm{RGO} / \mathrm{TiO}_{2}>\mathrm{TiO}_{2} / \mathrm{ZnO}>\mathrm{TiO}_{2}>\mathrm{ZnO}$. Photocatalytic efficiency of $\mathrm{Ag}_{2} \mathrm{CrO}_{4} / \mathrm{Ag} / \mathrm{BiFeO}_{3} @ \mathrm{rGO}$ heterojunction for ciprofloxacin (CIF) degradation under broad light spectrum was reported by Kumar, et al. [148]. Apart from the advantages of Z-scheme formation, the reductive and oxidative capabilities of the composite were triggered by the plasmonic $\mathrm{Ag}^{0}$ electron donation-mediation and the adsorption-electron mediation of reduced graphene oxide. 


\subsubsection{Noble Metal Based Photocatalysts}

The use of noble metals such as platinum (Pt) and silver $(\mathrm{Ag})$ as co-catalysts for graphene supported photocatalysts have been explored as photocatalyst for the degradation of pharmaceuticals because of their ability to enhance light absorption and improve rate of charge generation via their surface plasmon resonance (SPR) [149]. Xu, et al. [150] reported the enhanced degradation efficiency of Ag-BiOBr-rGO composite for the degradation of ketoprofen under simulated solar light irradiation. The catalytic study showed that $\mathrm{BiOBr}$ alone showed a degradation efficiency of 70\% towards ketoprofen after $120 \mathrm{~min}$, which was increased to $78 \%$ by the introduction of $5 \%$ rGO to the catalyst. Doping of Ag into the BiOBr-rGO photocatalyst at $5 \%$ mole fraction resulted in $100 \%$ degradation of the pollutant, with $65.8 \%$ mineralization efficiency. It was further observed that excess incorporation of $\mathrm{Ag}$ atoms into the composite resulted in decreased degradation efficiency due to electronic sinks being formed by the excess atoms. The composite also showed sufficient stability, with up to $100 \%$ efficiency still recorded after 3 cycles of usage. Similarly, Mohan, et al. [151] reported the degradation of oxytetracycline by $\mathrm{V}_{2} \mathrm{O}_{5} / \mathrm{rGO} / \mathrm{Pt}$ composites. The study focused on the effect of additives such as $\mathrm{H}_{2} \mathrm{O}_{2}, \mathrm{Na}_{2} \mathrm{CO}_{3}$, ethanol, persulfate and $\mathrm{NaCl}$ on the degradation efficiency of the photocatalyst. It was reported that additives that results in radical scavenging such as $\mathrm{NaCl}$ and $\mathrm{Na}_{2} \mathrm{CO}_{3}$ inhibited the degradation of the process, while additives with potential of increasing radical generation such as persulfate and $\mathrm{H}_{2} \mathrm{O}_{2}$ enhanced the degradation efficiency. For $\mathrm{H}_{2} \mathrm{O}_{2}$, the improvement in efficiency was limited to low concentrations because $\mathrm{H}_{2} \mathrm{O}_{2}$ quenches the ${ }^{\bullet} \mathrm{OH}$ generated in the system at high concentration. Evaluation of the photocatalyst for real effluent treatment showed a slightly reduction in efficiency from $99 \%$ for simulated water sample to $87 \%$.

\subsubsection{Metal Sulphide-Based Graphene Composite Photocatalyts}

Recently, metal sulphides have been explored as semiconductor materials due to their abundance, non-toxicity and low melting points, which allows for low temperature processing [152]. The use of graphene-supported ternary sulphide composites have also been explored as photocatalysts for pharmaceutical degradation. The degradation of 4 nitrophenol and 2-nitrophenol was studied using rGO supported $\mathrm{AgIn}_{5} \mathrm{~S}_{8}$ (rGO/AIS) as a photocatalyst [153]. The optimal rGO weight percentage in the composite was determined by photoluminescence (PL) quenching experiment, which showed that highest PL quenching was observed in the composite with $1 \%$ weight of rGO, signifying reduced electron-hole recombination. This confirmed that the lowest electron-hole recombination was observed in the $1 \% \mathrm{rGO} / \mathrm{AIS}$. The photocatalytic study showed that $91 \%$ degradation efficiency was achieved by the catalyst compared to $30.5 \%$ achieved by pristine AIS for 4-nitrophenol. The efficiency of degradation was 72.5 and $93.2 \%$ respectively for the degradation of 2 nitrophenol using AIS and 1\% rGO/AIS. The photocatalytic activity of photocatalysts with higher rGO weight percentage was reported to be lower compared to $1 \% \mathrm{rGO} / \mathrm{AIS}$, which was attributed to the covering of the catalyst surface by excess rGO, resulting in a suppression of visible light absorption, reduction of active site formation and increased electron-hole recombination. The degradation of naproxen by rGO supported $\mathrm{ZnIn}_{2} \mathrm{~S}_{4}$ (rGO/ZIS), showed that improved activity was achieved by rGO incorporation resulting in a degradation rate of $0.082 \mathrm{~min}^{-1}$, which was 1.3 times higher than the value reported for the unsupported catalyst and the degradation efficiency of the process reached $99 \%$ after $60 \mathrm{~min}$ [154]. Reactive species quenching experiments conducted in order to determine the active species responsible for the degradation showed that scavenging of ${ }^{\bullet} \mathrm{OH}$ from the process did not have any effect on the efficiency of the process, while scavenging of $\mathrm{h}^{+}$and $\mathrm{O}_{2}^{\bullet}$ - resulted in a significant reduction in degradation efficiency.

The compositing of two or more nanomaterials with differing dimensions through covalent and noncovalent interfaces could offer unique materials with new properties for different applications [155]. By compositing 3D bismuth oxyiodide, 2D graphene oxide (GO) and 1D bismuth sulphide, Arumugam, et al. [156] reported the synthesis of $\mathrm{Bi}_{2} \mathrm{~S}_{3} @ \mathrm{GO} / \mathrm{BiOI}$ with $2 \%$ and $1 \%$ weight composition of $\mathrm{Bi}_{2} \mathrm{~S}_{3}$ and GO respectively for the 
photodegradation of tetracycline under visible light radiation. The synergistic interaction between the multidimensional components of the catalyst resulted in enhanced charge transport and separation. The optimum composition of $\mathrm{GO}$ was determined by evaluating the photocatalytic activity of varying amount of $\mathrm{GO}$ with $\mathrm{BiOI}$ for tetracycline degradation and the highest degradation of $82 \%$ was observed for $1 \%$ wt GO, compared to 77 and $73 \%$ degradation for 2 and 3\% GO composition respectively. The 1\%GO-BiOI was then coupled with varying composition of $\mathrm{Bi}_{2} \mathrm{~S}_{3}$, with the $2 \%$ wt composition yielding the highest degradation efficiency of $98 \%$ for tetracycline degradation, compared to 88 and $89 \%$ degradation for 1 and $3 \% \mathrm{Bi}_{2} \mathrm{~S}_{3}$ composition respectively. The reaction rate constant for the photocatalyst based on differing $\mathrm{Bi}_{2} \mathrm{~S}_{3}$ composition was 0.171 .0 .350 and $0.224 \mathrm{~min}^{-1}$ for 1\%-Bi $\mathrm{S}_{3} @ 1 \%$-GO/BiOI, 2\%-Bi $2 \mathrm{~S}_{3} @ 1 \%$-GO/BiOI and 3\%-Bi ${ }_{2} \mathrm{~S}_{3} @ 1 \%-\mathrm{GO} / \mathrm{BiOI}$ respectively.

\subsubsection{Metal-Free Composites}

Kumar, et al. [157] reported a metal free self-assembled carbon quantum dots (CQD) and rGO layers modified $\mathrm{S} @ g-\mathrm{C}_{3} \mathrm{~N}_{4} / \mathrm{B} @ g-\mathrm{C}_{3} \mathrm{~N}_{4}$ composite as visible and solar light photocatalysts for the degradation of chloramphenicol (CMP). The study showed that 99.1 and $92.4 \%$ of CMP was degraded under visible and natural solar light respectively. Combination of rGO and CQD afforded the catalyst with better adsorption capacity, enhanced visible light absorption, improved charge flow via intimate interfacial contact, reduced charge recombination and increased ROS generation. The doping of $g-C_{3} \mathrm{~N}_{4}$ with different atoms resulted in different band structures, which grew into an effective Z-scheme when combined together. The formation of heterojunctions increases the chances of $\mathrm{O}_{2}^{\bullet}{ }^{-}$ and $\bullet \mathrm{OH}$ compared to individual g- $\mathrm{C}_{3} \mathrm{~N}_{4}$. Similarly, composites obtained from acidified g- $\mathrm{C}_{3} \mathrm{~N}_{4}(\mathrm{ACN})$, biochar, polyaniline (PANI) and rGO were explored to synthesis three metalfree photocatalysts: g- $\mathrm{C}_{3} \mathrm{~N}_{4} / \mathrm{ACN} / \mathrm{rGO} @$ Biochar (CARB), G- $\mathrm{C}_{3} \mathrm{~N} 4 / \mathrm{PANI} / \mathrm{rGO} @$ Biochar (CPRB) and CAN/PANI/rGO@Biochar (APRB) for degradation of ibuprofen [158]. Under Xenon lamp radiation, the APRB showed the highest efficiency of $98.4 \%$ degradation for $20 \mathrm{mg} / \mathrm{L}$ of ibuprofen after $50 \mathrm{~min}$, while the efficiencies of GARB and GPRB was about 70 and $62 \%$ respectively. The reaction rate for the degradation process by APRB was $0.08025 \mathrm{~min}^{-1}$, which was 2.4-fold of the value obtained for GARB. Although, the three composites showed the feasibility for Z-scheme mechanism, the favourable band edge positions, reduced charge carrier recombination, higher photo-response, and ordered structure resulting in improved charge flow along interfaces accounts for the higher activity of APRB.

Table 3 presents an overview of some photocatalytic processes that employ graphenebased composite. The photocatalytic processes are the most explored application of graphene-based composites in pharmaceutical degradation. It is observed that UV light source are still the most explored energy source for photocatalytic process, with only few studies employing visible/solar light sources. This shows the need for improved band gap tuning techniques which could enhance the utilization of visible/solar light sources, leading to an improvement in the economic visibility of this process. The wide range of pharmaceuticals that have been studied, the short reaction time and the high degradation efficiency of this process as presented in the table, is a proof of the great potential of this process for removal of pharmaceuticals from the environment. 
Table 3. Photocatalytic degradation of pharmaceuticals using graphene-based composites.

\begin{tabular}{|c|c|c|c|c|c|c|c|}
\hline Graphene Composite & Light Source & Pollutant & Process Parameters & Degradation Efficiency & Reaction Rate & Process Description & Ref. \\
\hline $\mathrm{ZnSnO}_{3} / \mathrm{RGO}$ & Mercury lamp $500 \mathrm{~W}$ & Metronidazole & $\begin{array}{c}\mid \text { Pol }|=5 \mathrm{mg} / \mathrm{L} ;| \text { Cat } \mid= \\
0.2 \mathrm{~g} ; \text { Time }=180 \mathrm{~min}\end{array}$ & $72.5 \%$ & - & $\begin{array}{l}\text { Photocatalytic activity of the catalyst was reportedly higher } \\
\text { under UV light radiation, which achieved complete } \\
\text { degradation after } 20 \mathrm{~min} \text {. compare to visible light radiation. } \\
\text { Improved photocatalytic activities was attributed to }\end{array}$ & [159] \\
\hline $\mathrm{AgFeO}_{2} / \mathrm{G} @ \mathrm{Cu}_{2}(\mathrm{BTC})_{3}$ & Halogen lamp; $500 \mathrm{~W}$ & $\begin{array}{l}\text { Diclofenac, } \\
\text { amoxicillin }\end{array}$ & $\begin{array}{l}|\mathrm{Pol}|=5 \mathrm{~g} / \mathrm{L} \\
\text { Time }=150 \mathrm{~min}\end{array}$ & $\begin{array}{l}91.4 \\
92.9\end{array}$ & $\begin{array}{l}8.7 \times 10^{-2} \min ^{-1} \\
6.5 \times 10^{-2} \min ^{-1}\end{array}$ & $\begin{array}{l}\text { enhanced charge transfer mechanism through direct } \\
\mathrm{Z} \text {-scheme from the } \mathrm{Cu}_{2}(\mathrm{BTC})_{3} \text { conduction band to the } \\
\mathrm{AgFeO}_{2} \text { valence band, with graphene acting as solid } \\
\text { electron mediator/acceptor }\end{array}$ & [160] \\
\hline ZnONP/GONS & $\begin{array}{l}\text { UV lamp }(254 \mathrm{~nm} ; \\
\left.1012 \mu \mathrm{W} / \mathrm{cm}^{-2}\right)\end{array}$ & Levofloxacin & $\begin{array}{c}|\mathrm{Cat}|=0.4 \mathrm{~g} / \mathrm{L} ; \\
|\mathrm{Pol}|=40 \mu \mathrm{g} / \mathrm{mL} \\
\mathrm{pH}=9.0 ; \mathrm{Temp} .=298 \mathrm{~K} \\
\text { Time }=120 \mathrm{~min}\end{array}$ & 99.2 & - & $\begin{array}{l}\text { A mixed fractional factorial designed was employed in } \\
\text { studying the effectiveness of combining } \mathrm{ZnO} \text { nanoparticles } \\
\text { with graphene oxide nanosheet. Factors such as pH, type } \\
\text { and concentration of nanoparticles, initial drug } \\
\text { concentration and exposure time. All factors showed } \\
\text { significant effect of degradation efficiency except pH and } \\
\text { exposure time. }\end{array}$ & [161] \\
\hline $\mathrm{V}_{2} \mathrm{O}_{5} / \mathrm{rGO} / \mathrm{Pt}$ & Xenon lamp; $150 \mathrm{~W}$ & Oxytetracycline & $\begin{array}{c}|\mathrm{Cat}|=0.5 \mathrm{~g} / \mathrm{L} \\
|\mathrm{Pol}|=50 \mu \mathrm{g} / \mathrm{mL} \\
\mathrm{pH}=9.0 ; \mathrm{Temp} .=298 \mathrm{~K} \\
\text { Time }=60 \mathrm{~min}\end{array}$ & 98 & $1.87 \times 10^{-2} \mathrm{~min}^{-1}$ & $\begin{array}{l}\text { Photocatalytic activity of } \mathrm{V}_{2} \mathrm{O}_{5} \text { was enhanced by } \\
\text { compositing with } \mathrm{rGO} \text { and Pt. Compositing with rGO } \\
\text { resulted in increased efficiency of } 90 \% \text { compare to } 58 \% \\
\text { observed for bare } \mathrm{V}_{2} \mathrm{O}_{5} \text {. The photocatalytic activity was } \\
\text { further increased to } 98 \% \text { by further doping of the } \\
\mathrm{rGO} / \mathrm{V}_{2} \mathrm{O}_{5} \text { with } 1 \% \mathrm{Pt} \text {. }\end{array}$ & [162] \\
\hline $\mathrm{GO}-\mathrm{ZnWO}_{4}$ & UV light & $\begin{array}{c}\text { Cetirizine } \\
\text { hydrochloride }\end{array}$ & $\begin{array}{c}\mid \text { Cat } \mid=425 \mathrm{mg} / \mathrm{L} ; \\
|\mathrm{Pol}|=10 \mathrm{mg} / \mathrm{L} \\
\mathrm{pH}=7.0 ; \text { Time = } 120 \mathrm{~min}\end{array}$ & 89 & - & $\begin{array}{l}\text { The photocatalytic activity of } \mathrm{GO}-\mathrm{ZnWO}_{4} \text { for cetirizine } \\
\text { hydrochloride degradation was optimized via a response } \\
\text { surface methodology. The model obtained for the process } \\
\text { showed that factors such as pollutant concentration, } \\
\text { catalyst dose, pH and irradiation time influenced the } \\
\text { degradation process with interactions effects also existing } \\
\text { between all the process parameters }\end{array}$ & [163] \\
\hline $\mathrm{TiO}_{2} / \mathrm{Fe}_{2} \mathrm{O}_{3} / \mathrm{GO}$ & $\begin{array}{c}\text { UV lamp (15 W; } \\
254 \mathrm{~nm} \text { wavelenght) }\end{array}$ & Metronidazole & $\begin{array}{c}|\mathrm{Cat}|=1 \mathrm{~g} / \mathrm{L} ; \\
|\mathrm{Pol}|=10 \mathrm{mg} / \mathrm{L} \\
\mathrm{pH}=5.0 ; \text { Time = } 120 \mathrm{~min}\end{array}$ & 97 & - & $\begin{array}{l}\text { The effect of mineral salts such as } \mathrm{NaCl}, \mathrm{CaCl}_{2}, \mathrm{KcL} \text {, } \\
\mathrm{NaHCO}_{3}, \mathrm{MgSO}_{4} \text { and } \mathrm{Na}_{2} \mathrm{SO}_{4} \text { on the degradation efficiency } \\
\text { of the catalyst was explored at concentration range of } \\
50-800 \mathrm{mg} / \mathrm{L} \text {. The efficiency of the process decreased with } \\
\text { increase in mineral salt concentration for } \mathrm{Na}_{2} \mathrm{SO}_{4}, \mathrm{MgSO}_{4} \\
\text { and } \mathrm{NaHCO}_{3} \text { resulting in } 42.43,38.08 \text { and } 37.73 \text { efficiency } \\
\text { reduction respectively. For minerals such as } \mathrm{NaCl} \text { and } \mathrm{KCl} \text {, } \\
\text { efficiency was reduced up to concentration level of } \\
200 \mathrm{mg} / \mathrm{L} \text {, after which an upward trend in photocatalytic } \\
\text { activity was reported. The effects of these mineral salts were } \\
\text { correlated with their influence on the pH of the process. }\end{array}$ & [164] \\
\hline Pt-rGO-TiO ${ }_{2}$ & $\begin{array}{l}\text { Low pressure mercury } \\
\text { vapour UV lamp } \\
(254 \mathrm{~nm}, 8 \mathrm{~W}) \text { and } \\
\text { simulated light }\end{array}$ & Propranolol & $\begin{array}{c}\text { Cat } \mid=0.4 \mathrm{mg} / \mathrm{mL} ; \\
\mid \text { Pol } \mid=0.05 \mathrm{mmol} ; \\
\mathrm{pH}=5.0 ; \text { Time }=120 \mathrm{~min}\end{array}$ & $\begin{array}{l}\text { 79\% under UV irradiation } \\
\text { and } 94 \% \text { under simulated } \\
\text { solar light }\end{array}$ & - & $\begin{array}{l}\text { The efficiency of the catalyst for propranolol degradation } \\
\text { was observed to be higher under simulated solar light }(94 \%) \\
\text { compare to UV light }(79 \%) \text {. By rational design of the ternary } \\
\text { heterostructure, with good efficiency in the UV spectrum } \\
\text { and with renewable solar energy can be obtained }\end{array}$ & [165] \\
\hline $\mathrm{Ag} / \mathrm{AgBr} / \mathrm{GO}$ & Direct solar radiation & Diclofenac & $\begin{array}{c}\text { Cat } \mid=1.0 \mathrm{~g} / \mathrm{L} ; \\
\mid \text { Pol } \mid=25 \mathrm{mg} / \mathrm{L} ; \\
\mathrm{pH}=7.0 ; \text { Time }=6 \mathrm{~min}\end{array}$ & 95 & - & $\begin{array}{l}\text { A facile ultrasonic irradiation-based processes was explored } \\
\text { in the synthesis of the photocatalyst. The incorporation of } \\
G O \text { into the catalyst enhanced the photocatalytic activity of } \\
\text { the composite by improving the adsorptive capacity of the } \\
\text { catalyst via intermolecular } \pi-\pi \text { interaction with diclofenac. } \\
\text { Improved charge transport and reduced charge carrier } \\
\text { recombination were other effects of } G O \text { in the catalyst. }\end{array}$ & [166] \\
\hline
\end{tabular}


Table 3. Cont

\begin{tabular}{|c|c|c|c|c|c|c|c|}
\hline Graphene Composite & Light Source & Pollutant & Process Parameters & Degradation Efficiency & Reaction Rate & Process Description & Ref. \\
\hline GO-P25 & $\begin{array}{l}\text { Medium-pressure } \\
\text { mercury vapour lamp } \\
\left(50 \mathrm{~mW} / \mathrm{cm}^{2} ; 350 \mathrm{~nm}\right)\end{array}$ & Diphenhydramine & $\begin{array}{l}\text { Cat }|=1.0 \mathrm{~g} / \mathrm{L} ;| \mathrm{Pol} \mid= \\
\quad 3.40 \times 10^{-4} \mathrm{~mol} / \mathrm{L} ; \\
\mathrm{pH}=7.0 ; \text { Time }=60 \mathrm{~min}\end{array}$ & 90 & $54 \times 10^{-3} \min ^{-1}$ & $\begin{array}{l}\text { Composites were prepared by a simple mixing and } \\
\text { sonication method. Varying the GO content and } \\
\text { heat-treatment under nitrogen altered the activity of the } \\
\text { photocatalyst. Activity of the catalyst was enhanced by GO } \\
\text { reduction and the high contact between } \mathrm{TiO}_{2} \text { and carbon } \\
\text { phase }\end{array}$ & [167] \\
\hline rGO- $\mathrm{TiO}_{2}$ & $\begin{array}{l}\text { For UV/Vis process: } \\
\text { Medium-pressure } \\
\text { mercury vapour lamp } \\
\left.\text { (50 mW/ } / \mathrm{cm}^{2} ; 350 \mathrm{~nm}\right) \\
\text { For visible light } \\
\text { process: Cut-off long } \\
\text { pass filter }(\lambda=430 \mathrm{~nm} \text {; } \\
\left.6 \mathrm{~mW} / \mathrm{cm}^{2}\right)\end{array}$ & Diphenhydramine & $\begin{array}{l}\text { Cat }|=15 \mathrm{mg} ;| \mathrm{Pol} \mid= \\
\quad 3.40 \times 10^{-4} \mathrm{~mol} / \mathrm{L} ; \\
\mathrm{pH}=7.0 ; \text { Time }=60 \mathrm{~min}\end{array}$ & $\begin{array}{l}100 \text { under UV } / \text { Vis } \\
\text { irradiation } \\
40 \% \text { under Visible light } \\
\text { radiation }\end{array}$ & $\begin{array}{l}62.3 \times 10^{-3} \mathrm{~min}^{-1} \\
3.4 \times 10^{-3} \mathrm{~min}^{-1}\end{array}$ & $\begin{array}{l}\text { Under both near-UV/Vis and visible light irradiation, the } \\
\text { activity of the catalyst was composition dependent. Under } \\
\text { UV/Vis irradiation photogenerated holes were the primary } \\
\text { active species, while under visible light radiation, radical } \\
\text { mediated oxidation of the pollutant was observed }\end{array}$ & [168] \\
\hline $\mathrm{Ag}_{2} \mathrm{O} / \mathrm{ZnO} / \mathrm{rGO}$ & $500 \mathrm{~W}$ xenon lamp & Bisphenol A & $\begin{array}{c}\text { Cat } \mid=0.8 \mathrm{~g} / \mathrm{L} \mathrm{mg} \\
\mid \text { Pol } \mid=10 \mathrm{mg} / \mathrm{L} \\
\text { Time }=180 \mathrm{~min}\end{array}$ & $80 \%$ & $0.084 \mathrm{~min}^{-1}$ & $\begin{array}{l}\text { The photocatalyst was prepared through a rapid } \\
\text { hydrothermal process. The band gap of } \mathrm{ZnO} \text { was reduced } \\
\text { by Ag doping, while rGO reduced the electron-hole pair } \\
\text { recombination. Optimum doping of } 5 \% \text { and } 3 \% \text { percent was } \\
\text { reported for } \mathrm{Ag} \text { and rGO respectively }\end{array}$ & [169] \\
\hline Graphene_SBA/ $\mathrm{TiO}_{2}$ & Xenon lamp & Tetracycline & $\begin{aligned} \text { Cat } \mid & =50 \mu \mathrm{g} ;|\mathrm{Pol}| \\
& =30 \mu \mathrm{g} / \mathrm{L} ; \\
& \text { Time }=60 \mathrm{~min}\end{aligned}$ & $89 \%$ & $0.0367 \mathrm{~min}^{-1}$ & $\begin{array}{l}\text { The composite exhibited high activity dye to increased } \\
\text { adsorption of the pollutant via } \pi-\pi \text { interaction. The } \\
\text { SBA//TiO2 acted as a medium for migration of the } \\
\text { photogenerated carriers, while the graphene sheet increased } \\
\text { the number of active site }\end{array}$ & [170] \\
\hline rGO/GNW hydrogel & $\begin{array}{l}\text { UV lamp ( } 24 \mathrm{~W} \\
\text { wavelength of } 254 \mathrm{~nm})\end{array}$ & Ethenzamide & $\begin{array}{l}\text { Cat } \mid=10 \mathrm{mg} / \\
|\mathrm{Pol}|=500 \mathrm{ppb} \\
\text { Time }=120 \mathrm{~min}\end{array}$ & 99.0 (under UV light) & $1.014 \mathrm{~min}^{-1}$ & $\begin{array}{l}\text { Graphene/ } / \mathrm{Ti}_{2} \text { nanowire was implanted into graphene } \\
\text { hydrogel to obtained a } 3 \mathrm{D} \text { network with enhanced catalytic } \\
\text { activity under VUV, UV and Vis-NIR light irradiation. The } \\
\text { hydrogel was effectual in overcoming the mass transfer } \\
\text { resistance due to the low concentration of the pollutant }\end{array}$ & [171] \\
\hline $\mathrm{N}-\mathrm{TiO}_{2} / \mathrm{GR}$ & $50 \mathrm{~W}$ mercury lamp & $\begin{array}{l}\text { Mixture of } \\
\text { oxytetracycline } \\
\text { chlortetracycline, } \\
\text { sulfamethazine, } \\
\text { norfloxacin }\end{array}$ & $\begin{array}{c}\mid \text { Cat }|=-;| \mathrm{Pol} \mid= \\
30 \mathrm{mg} / \mathrm{L} ; \\
\mathrm{pH}=11 \\
\text { Time }=160 \mathrm{~min}\end{array}$ & $\begin{array}{l}65 \% \\
55 \\
45 \\
65\end{array}$ & $\begin{array}{l}0.0063 \mathrm{~min}^{-1} \\
0.0053 \mathrm{~min}^{-1} \\
0.0032 \mathrm{~min}^{-1} \\
0.0052 \mathrm{~min}^{-1}\end{array}$ & $\begin{array}{l}\mathrm{N}-\mathrm{TiO}_{2} / \mathrm{Gr} \text { with large surface area was prepared by } \\
\text { depositing monolayer graphene on } \mathrm{N}-\mathrm{TiO}_{2} \text { thin film. The } \\
\text { catalyst showed enhanced photocatalytic activity towards } \\
\text { the degradation of a mixture of pharmaceuticals }\end{array}$ & [172] \\
\hline $\mathrm{Ag}_{3} \mathrm{PO}_{4} /$ graphene oxide & $\begin{array}{l}\text { White LED lamps } \\
\quad(12-\mathrm{W})\end{array}$ & Ketoconazole & $\begin{array}{c}|\mathrm{Cat}|=1.62 \mathrm{~g} / \mathrm{L} \\
|\mathrm{Pol}|=5.87 \mathrm{mg} / \mathrm{L} \\
\mathrm{pH}=8 \\
\text { Time }=93.34 \mathrm{~min}\end{array}$ & 96.53 & $0.024 \mathrm{~min}^{-1}$ & $\begin{array}{l}\text { The photocatalytic activity of the } \mathrm{Z} \text {-scheme } \mathrm{Ag}_{3} \mathrm{PO}_{4} / \mathrm{GO} \\
\text { was studied using the central composite design for } \\
\text { modeling and optimization. The predicted optimum } \\
\text { degradation correlated well with the experimental } \\
\text { degradation carried out at the predicted conditions }\end{array}$ & [173] \\
\hline G/A/TNS & $\begin{array}{l}\text { Simulated visible light } \\
\text { (Xenon lamp } 450 \mathrm{~W}, \\
\text { radiation intensity- } \\
90 \mathrm{~mW} / \mathrm{cm}^{2}\end{array}$ & Sulfamethazine & $\begin{array}{c}\mid \text { Cat } \mid=0.8 \mathrm{~g} / \mathrm{L} \\
|\mathrm{Pol}|=5 \mathrm{mg} / \mathrm{L} \\
\mathrm{pH}=8 \\
\text { Time }=240 \mathrm{~min}\end{array}$ & 96.1 & $0.493 \mathrm{~h}^{-1}$ & $\begin{array}{l}\text { The incorporation of graphene into the composite resulted } \\
\text { in band gap reduction from } 3.1 \text { to } 2.8 \mathrm{eV} \text { at the optimum } \\
\text { graphene concentration of } 0.5 \mathrm{wt} \%\end{array}$ & [174] \\
\hline $\mathrm{GO} @ \mathrm{Fe}_{3} \mathrm{O}_{4} / \mathrm{ZnO} / \mathrm{SnO}_{2}$ & $\begin{array}{l}\text { UV-C irradiation }(6 \mathrm{~W} \\
\text { lamps) }\end{array}$ & Azithromycin & $\begin{array}{c}\mathrm{Cat} \mid=1 \mathrm{~g} / \mathrm{L} \\
|\mathrm{Pol}|=30 \mathrm{mg} / \mathrm{L} \\
\mathrm{pH}=3 \\
\text { Time }=120 \mathrm{~min}\end{array}$ & 90.06 & $0.027 \mathrm{~min}^{-1}$ & $\begin{array}{l}\text { The catalytic activity of the composite was evaluated for } \\
\text { both batch and continuous processes. The breakthrough } \\
\text { time was influenced by the bed height, flow rate and the } \\
\text { initial concentration of the pollutant. }\end{array}$ & [175] \\
\hline $\mathrm{rGO} / \mathrm{Fe}_{3} \mathrm{O}_{4}$ & $\begin{array}{l}\text { Direct solar light } \\
\text { (intensity }=850 \\
\left.\quad \mathrm{~W} / \mathrm{m}^{2}\right)\end{array}$ & Carbamazepine & $\begin{array}{c}\mathrm{Cat} \mid=1 \mathrm{~g} / \mathrm{L} \\
|\mathrm{Pol}|=30 \mathrm{mg} / \mathrm{L} \\
\text { Time }=180 \mathrm{~min} ; \mathrm{pH}=6.5\end{array}$ & $90 \%$ & $0.0021 \mathrm{~min}^{-1}$ & $\begin{array}{l}\text { The optimum incorporation of reduced graphene oxide lead } \\
\text { to improve surface area of the composite. Enhanced } \bullet^{\bullet} \mathrm{OH} \\
\text { radical and holes generation accounted for the improved } \\
\text { activity }\end{array}$ & [176] \\
\hline
\end{tabular}


Table 3. Cont.

\begin{tabular}{|c|c|c|c|c|c|c|c|}
\hline Graphene Composite & Light Source & Pollutant & Process Parameters & Degradation Efficiency & Reaction Rate & Process Description & Ref. \\
\hline $\mathrm{BVO} / \mathrm{rGO}$ & $\begin{array}{l}\text { Fluorescent lamp } \\
\text { (55 W; } 550 \mathrm{~nm} \\
\text { wavelength) }\end{array}$ & Tetracycline & $\begin{array}{c}\mid \text { Cat } \mid=45 \mathrm{mg} / \mathrm{L} ; \\
\mid \text { Pol } \mid=25 \mathrm{mg} / \mathrm{L} ; \\
\text { Time }=85 \mathrm{~min} ; \mathrm{pH}=10.5\end{array}$ & 99 & - & $\begin{array}{l}\text { A bismuth vanadate (BVO) composited with } \mathrm{rGO} \text { was } \\
\text { synthesized via a facile process. The catalyst showed a } \\
\text { degradation efficiency strongly influenced by the } \mathrm{pH} \text { of the } \\
\text { process. }\end{array}$ & [177] \\
\hline $\begin{array}{c}\mathrm{Fe}_{3} \mathrm{O}_{4} @ \mathrm{rGO} @ \mathrm{ZnO} / \mathrm{Ag}- \\
\mathrm{NPs}\end{array}$ & $\begin{array}{c}\text { LEDs (light intensity = } \\
12 \mu \mathrm{W} / \mathrm{cm}^{2} \text { and } \\
365 \mathrm{~nm} \text { emission peak } \\
\text { Tungsten xenon lamp } \\
\quad(300 \mathrm{~W})\end{array}$ & Metformin & $\begin{array}{c}\mid \text { Cat } \mid=40 \mathrm{mg} / \mathrm{L} ; \\
\mid \text { Pol } \mid=20 \mathrm{mg} / \mathrm{L} ; \\
\text { Time = } 60 \mathrm{~min} ; \mathrm{pH}=5.4\end{array}$ & $\begin{array}{l}100 \\
100\end{array}$ & $\begin{array}{l}0.065 \mathrm{~min}^{-1} \\
0.055 \mathrm{~min}^{-1}\end{array}$ & $\begin{array}{l}\text { The catalytic activity of the composite was improved by the } \\
\text { synergistic improvement of light absorption and adsorption } \\
\text { capacity. The magnetic nature of the composite also made } \\
\text { separation easier to achieve. }\end{array}$ & [178] \\
\hline $\mathrm{ZnFe}_{2} \mathrm{O}_{4}$-GR & Xenon lamp (300 W) & Paracetamol & $\begin{array}{l}\mid \text { Cat } \mid=1 \mathrm{mg} / \mathrm{L} ; \\
\mid \text { Pol } \mid=10 \mathrm{mg} / \mathrm{L} \\
\text { Time }=180 \mathrm{~min}\end{array}$ & 97.4 & - & $\begin{array}{l}\text { A nano-hybrid with photocatalytic activity that increased } \\
\text { with weight percentage of graphene was synthesized } \\
\text { though } \mathrm{ZnFe}_{2} \mathrm{O}_{4} \text { is photo-catalytically inactive under } \\
\text { visible light radiation. The optimal graphene concentration } \\
\text { was at } 4 \mathrm{w} \% \text { of the catalyst composition }\end{array}$ & [179] \\
\hline
\end{tabular}




\subsection{Electrocatalytic Process}

The Fenton process is one of the prominent AOPs for the degradation of contaminants. The process involves the generation of reactive ${ }^{\bullet} \mathrm{OH}$ radicals by the reaction of hydrogen peroxide with ferrous iron catalyst (Equations (3) and (4)). The formation of large ferric hydroxide sludge, narrow $\mathrm{pH}$ requirement, large Fenton reagent consumption and high risk involved in production, transportation and storage of $\mathrm{H}_{2} \mathrm{O}_{2}$ are serious drawbacks for the process despite its high potential [180].

$$
\begin{gathered}
\mathrm{Fe}^{2+}+\mathrm{H}_{2} \mathrm{O}_{2} \rightarrow \mathrm{Fe}^{3+}+\mathrm{HO}^{-}+{ }^{\bullet} \mathrm{OH} \\
\mathrm{Fe}^{3+} \mathrm{H}_{2} \mathrm{O}_{2} \rightarrow \mathrm{Fe}^{2+} \mathrm{HO}_{2}^{\bullet}+\mathrm{H}^{+}
\end{gathered}
$$

With the electro-Fenton process (EF), $\mathrm{H}_{2} \mathrm{O}_{2}$ for the Fenton process is electrogenerated in the reaction system via the two-electron oxygen reduction reaction at the cathode (Equation (5)). Thus, circumventing the challenges associated with $\mathrm{H}_{2} \mathrm{O}_{2}$ addition in the Fenton process [181]. The continuous reduction of $\mathrm{Fe}^{3+}$ to $\mathrm{Fe}^{2+}$ at the surface of the cathode via the direct one electron reduction or by reaction with $\mathrm{H}_{2} \mathrm{O}_{2}$ (Equation (4)) is the main driving force behind the EF process [182]. The EF process has gained much attention due to its high efficiency, low cost and facile operating conditions $[183,184]$. Also, advances in electro-Fenton electrode development has led to composite electrodes into which solid Fenton catalysts are immobilized such as ferrite-carbon aerogel [185], $\mathrm{Fe}_{3} \mathrm{O}_{4} @$ carbon fiber paper@polyaniline [186], $\mathrm{Fe}_{3} \mathrm{O}_{4} @ \mathrm{Fe}_{2} \mathrm{O}_{3} /$ activated carbon aerogel [187]. These functionalized cathodes have the potential of achieving the Fenton reaction over a wide $\mathrm{pH}$ range.

$$
\begin{gathered}
\mathrm{O}_{2}+2 \mathrm{H}^{+}+2 \mathrm{e}^{-} \rightarrow \mathrm{H}_{2} \mathrm{O}_{2} \\
\mathrm{Fe}^{3+}+\mathrm{e}^{-} \rightarrow \mathrm{Fe}^{2+}
\end{gathered}
$$

The degradation of acetaminophen in an electro-Fenton process employing heteroatomdoped graphene aerogel cathode and carbon-magnetite catalyst, showed complete degradation was achieved in $240 \mathrm{~min}$, while $45.5 \%$ mineralization efficiency was achieved in $360 \mathrm{~min}$ [188]. The degradation efficiency was influenced by the amount and nature of heteroatom, while the mineralization efficiency was strongly correlated to the amount of iron leached from the catalyst. The degradation efficiency of homogeneous and heterogeneous electro-Fenton process using $\mathrm{FeSO}_{4} \bullet 7 \mathrm{H}_{2} \mathrm{O}$ and graphene oxide- $\mathrm{Fe}_{3} \mathrm{O}_{4}$ composite respectively as catalyst for the degradation of chloramphenicol and metronidazole was reported by Görmez, et al. [189]. The study showed that 57 and $71 \%$ mineralization was obtained for the degradation of $80 \mathrm{~g} / \mathrm{L}^{-1}$ metronidazole and chloramphenicol after $300 \mathrm{~min}$ for the homogenous process. Under the same reaction condition, the graphene oxide- $\mathrm{Fe}_{3} \mathrm{O}_{4}$ heterogeneous catalyst achieved 73 and $86 \%$ mineralization efficiency for metronidazole and chloramphenicol respectively, with degradation efficiency reaching above $99 \%$. The process was observed to be greatly influenced by the $\mathrm{pH}$ of the system, with optimum $\mathrm{pH}$ being 3 . This was attributed to the positive charge induced on the surface of the catalyst at low $\mathrm{pH}$, thus favouring an electrostatic interaction with the pollutant molecules which were also present in their ionic form.

A novel $\gamma$-FeOOH graphene polyacrylamide carbonized aerogel was reported as air-cathode for the degradation of sulfamethoxazole (SMX) [190]. The study showed a gradual increase in the conductivity, and specific surface area of the cathode material until an optimum concentration of $5 \mathrm{mg} / \mathrm{mL}^{-1} \mathrm{GO}$ was reached. Above this optimum GO concentration, a notable decrease in surface area was observed despite the increase in conductivity. This was attributed to the reduced incorporation of GO into the hydrogel when excess $\mathrm{GO}$ was employed. When the catalytic activity of the catalyst was evaluated using $0.15 \mathrm{~g}$ of the catalyst on $500 \mathrm{~mL}$ of $0.1 \mathrm{mM} \mathrm{SMX}$ at $200 \mathrm{~mA}$, a complete degradation was achieved after about $120 \mathrm{~min}$ with a degradation rate constant of $0.51 \times 10^{-1} \mathrm{~min}^{-1}$. In another study, Mi, et al. [191], reported the mechanism of degradation of ciprofloxacin (CIP) by RGO-Ce/ $\mathrm{WO}_{3}$ nanosheets modified carbon felt cathode. It was observed that the 
degradation process progressed by the oxidative degradation of the piperazine ring and oxidative cleavage of the cyclopropane ring of CIP. As shown in Figure 10, the oxidative degradation process was achieved via hydroxylation, decarboxylation and $\mathrm{N}$-dealkylation processes.<smiles>C#CC1CC1n1cc(C(=O)O)c(=O)c2cc(F)c(N3CCNCC3)cc21</smiles>

Figure 10. Mechanism of degradation of ciprofloxacin in an $\mathrm{RGO}-\mathrm{Ce} / \mathrm{WO}_{3}$ nanosheets modified carbon felt cathode based Electro-Fenton process. Reprinted with permission from Mi, et al. [191]. Copyright (2019) Elsevier.

Aside from electro-Fenton processes, graphene-based composites have also been explored as anodic membranes for the electrochemical oxidation of pharmaceuticals. The excellent electrical conductivity of graphene and electrooxidation capacity of $\mathrm{SnO}_{2}$ were explored in a G/SnO $/$ CFs composite for the electrochemical degradation of SMX [192]. The membrane showed improved degradation efficiency of $85 \%$ and high stability, withstanding 10 cycles without any significance loss of activity. Mechanism study showed that two transformation pathways: hydroxyl radical attack and ring cleavage were the identified routes for the degradation process. Presented in Table 3, are the process overview 
of other electro-Fenton process employing graphene-based composites are presented in Table 4 and the potential application of graphene-based composites as catalysts, electrodes or membranes in this process, shows the significant role these composites can play in the further development of these AOP technique.

Table 4. Fenton processes based on graphene composites for degradation of pharmaceuticals.

\begin{tabular}{|c|c|c|c|c|c|c|c|}
\hline $\begin{array}{l}\text { Graphene } \\
\text { Composite }\end{array}$ & Role & Pollutant & Process Parameters & $\begin{array}{l}\text { Amount of } \\
\mathrm{H}_{2} \mathrm{O}_{2} \text { Generated } \\
\left(\mathrm{mg} / \mathrm{h} / \mathrm{cm}^{2}\right)\end{array}$ & Efficiency & Reaction Rate & Ref. \\
\hline 3D-GN@nZVI & Catalyst & Sulfadiazine & $\begin{array}{c}\mid \text { Cat }|=0.5 \mathrm{~g} / \mathrm{L} ;| \mathrm{Pol} \mid=10 \mathrm{mg} / \mathrm{L} \\
\mathrm{pH}=3.0 ; \text { Temp. }=298 \mathrm{~K} ; \text { Time }=120 \mathrm{~min} \\
\mid \text { Pol } \mid=10 \mathrm{mg} / \mathrm{L} ; \mathrm{pH}=7.0 ;\end{array}$ & - & 81 & - & [193] \\
\hline Fc-ErGO & Cathode & Ciprofloxacin & $\begin{array}{l}\text { Temp. }=298 \mathrm{~K} \\
\text { Time }=180 \mathrm{~min}\end{array}$ & - & 99 & $0.035 \mathrm{~min}^{-1}$ & [194] \\
\hline 3D-graphene & Cathode & Nalidixic acid & $\begin{array}{c}\mid \text { Pol } \mid=15 \mathrm{mg} / \mathrm{L} ; \mathrm{pH}=3.5 \\
\text { Current intensity }=300 \mathrm{~mA} \text { Temp. } \\
=298 \mathrm{~K} \\
\text { Time }=300 \mathrm{~min}\end{array}$ & 28.19 & 90 & - & [195] \\
\hline Fc-ErGO & $\begin{array}{l}\text { Rotating } \\
\text { disc } \\
\text { electrode }\end{array}$ & $\begin{array}{l}\text { Ciprofloxacin, } \\
\text { carbamazepine }\end{array}$ & $\begin{array}{c}|\mathrm{Pol}|=10 \mathrm{mg} / \mathrm{L} ; \mathrm{pH}=3.0 ; \\
\text { Current intensity }=1.5 \mathrm{VTemp} .=298 \mathrm{~K} \\
\text { Time }=60 \mathrm{~min}\end{array}$ & $175 \mathrm{mg} / \mathrm{L}$ & $\begin{array}{l}99.9 \\
99.9\end{array}$ & $\begin{array}{l}0.199 \min ^{-1} \\
0.082 \min ^{-1}\end{array}$ & [182] \\
\hline Cu-rGO & electrode & Diclofenac & $\begin{array}{l}\mid \text { Pol } \mid=0.2-200 \mathrm{mg} / \mathrm{L} ; \mathrm{pH}=5.0-11.0 \\
\text { Voltage }=-0.5-1.0 \mathrm{~V} ; \text { Time }=60 \mathrm{~min}\end{array}$ & - & 100 & $2.2-8.1 \times 10^{-3}$ & [196] \\
\hline
\end{tabular}

\subsection{Sonocatalytic/Sono-Photocatalytic Process}

Different studies have shown that by combining ultrasonic irradiation with other AOPs such as ultrasonic/photocatalysis, ultrasonic/Fenton process and ultrasonic/catalysis, the efficiency of contaminant sdegradation could be enhanced. Coupling of ultrasonication with other AOPs often leads to: (i) an increase in mass transfer of pollutants between catalysts surface and liquid phase, (ii) enhancement of reactive radical generation, and (iii) de-aggregation of the nanocomposite particles. The sonocatalytic degradation of sulfasalazine and diclofenac by $\mathrm{Ag}_{2} \mathrm{O} / \mathrm{CdO} / \mathrm{CeO}_{2} / \mathrm{rGO}$ was reported by Mirzazadeh and Lashanizadegan [197] with efficiencies of $100 \%$ and $\sim 85 \%$ reported for sulfasalazine and diclofenac respectively. The efficiency of the process was significantly influenced by the weight percent of $\mathrm{Ag}$ in the composite and the optimum composition of $\mathrm{Ag}$ was reported to be $5 \%$. Kinetic studies showed a reaction rate constant of 0.11 and $0.018 \mathrm{~min}^{-1}$ for sulfasalazine and diclofenac respectively. The effect of sonolytic frequency on the degradation of carbamazepine and acetaminophen by $\mathrm{GO} / \beta-\mathrm{Bi}_{2} \mathrm{O}_{3} / \mathrm{TiO}_{2} / \mathrm{Bi}_{2} \mathrm{Ti}_{2} \mathrm{O} /$ heterojunction was reported by Lee, et al. [198]. Although, increasing the frequency leads to the enhancement of acoustic cavitation and subsequently the catalytic activity, increasing the frequency beyond an optimal level resulted in reduced activity due to the reduction in the occurrence of collapsing events, which may result to reduced number of small cavity bubbles. Comparing degradation at frequencies of 28, 580 and $970 \mathrm{kHz}$, the process at $580 \mathrm{kHZ}$ was found to be most effective for carbamazepine and acetaminophen degradation.

Moradi, et al. [199] reported the sonophotocatalytic degradation of sulfamethoxazole using $\mathrm{MgO} / \mathrm{ZnO} / \mathrm{Graphene}$ nanocomposite. Incorporation of graphene and $\mathrm{ZnO}$ with $\mathrm{MgO}$ enhanced its catalytic activity under both UV and visible light radiation. Complete degradation of SMX was achieved after $120 \mathrm{~min}$. The ultrasound played an important role in ensuring clean-up of the catalyst surface and jointly enhanced the production of reactive radicals with the light source. The photocatalytic interaction between the composite and light source was also significant in enhancing the efficiency of the process.

\section{Factors Influencing the Degradation of Pharmaceuticals}

Generally, the efficiency of any advanced oxidation process is significantly influenced by factors that may influence the reactive radical generation. These factors are often referred to as controlling parameters and the most studied parameters include concentration of the pharmaceutical, catalyst concentration, dissolved oxygen levels, $\mathrm{pH}$, concentration of oxidants, water matrix, light source and intensity. 


\subsection{Concentration of Pharmaceuticals}

High initial concentration of pollutants usually lead to a higher rate of adsorption on the catalyst surface. However, a commensurate increase in reactive radical generation is usually needed to sustain the degradation process. Therefore, increasing the initial concentration of the pollutant usually result in increased degradation burden on a unit catalyst due to limitation in the amount of reactive species generated in the process. Also, the coverage of the catalyst surface by the adsorbed molecules have also been suggested to be capable of blocking the catalyst surface from receiving sufficient light energy for generation of reactive radical species in photon-based processes [200]. Therefore, Increasing the concentration of pollutant has been found to generally result in process efficiency reduction.

\subsection{Effect of $p H$}

It is well established that the adsorption and surface charge of a catalyst is greatly influenced by the system $\mathrm{pH}$. Also, the ionic form of the pollutant in solution is significantly influenced. At $\mathrm{pH}$ value equal to the point of zero charge $\left(\mathrm{pH}_{\mathrm{pzc}}\right)$ of the catalyst, surface charge is usually zero, while $\mathrm{pH}$ values lower or higher than the $\mathrm{pH}_{\mathrm{pzc}}$ leaves a net positive or negative charge on the catalyst [201]. Kaur, et al. [202] confirmed this trend in the study of the effect of $\mathrm{pH}$ on the degradation of triclosan using $\mathrm{rGO}^{-\mathrm{TiO}_{2}}$ composite. At a $\mathrm{pH}$ value below the $\mathrm{pH}_{\mathrm{pzc}}$ of the catalyst complete degradation was achieved, while the degradation was significantly suppressed at higher $\mathrm{pH}$. In the degradation of amoxillin by graphene-titanium oxide nanotubes composites, Song, et al. [203] reported a gradual increase in degradation efficiency with increase in $\mathrm{pH}$ from 3 to 9; however, increasing the $\mathrm{pH}$ to11 resulted in a decrease in efficiency due to the similar charge on the catalyst and amoxicillin molecule. Therefore, depending on the ionic state of the pollutant and the net charge on the catalyst surface, the adsorption of the pollutant which is significant for the degradation process needs to be altered towards the enhancement of the degradation process.

\subsection{Effect of Catalyst Concentration}

Effect of catalyst concentration on the degradation efficiency usually varies for photonbased processes and non-photo-based processes. While in general, the increase in the catalyst concentration increases the quantity of reactive radical species generated in a system, in photon-based processes, increasing the catalyst concentration beyond certain concentration level is found to reduce the degradation efficiency. This is due to reduced light peneteration into the reaction system, leading to reduced radical generation. In the study by Sayadi, et al. [175], increasing the catalyst concentration from $0.25 \mathrm{~g} / \mathrm{L}$ to $0.75 \mathrm{~g} / \mathrm{L}$ led to an increase in degradation efficiency. However, beyond this concentration level, a reduction in catalytic activity was observed due to increased turbidity of the solution, which reduces light penetration and dispersion.

\subsection{Dissolved Oxygen}

Dissolved oxygen (DO) in a catalytic system acts as an electron acceptor, thus reducing the rate of electron-hole recombination, which enhances the degradation efficiency of a process. Also, dissolved oxygen could help in radical intermediate stabilization; aromatic ring cleavage induction and mineralization [204,205]. Azim, et al. [206] reported an increase in the catalytic activity of $\mathrm{GO}$ as the level of DO in the system was increased. However, Lee, et al. [207] observed that in processes that employed DO generator in order to improve level of DO, bubbles formed by the generator got attached to the catalyst surface, thereby reducing the efficiency of the process. At high DO concentration level, this effect was mitigated and enhanced catalytic activity was observed. Subramanian and Kannan [208], reported that the level of DO in a system is important for processes involving high light intensities due to the large quantities of holes and electrons generated, as the electron scavenging role of dissolved oxygen becomes significant. 


\subsection{Light Intensity}

Light intensity is an important factor to be optimized for a photocatalytic process as it contirbutes significantly to the overall cost of a process. Thus, its effective use is a major factor to be considered in the design and operation of a process. In terms of the effect of light intensity on reaction rate, three types of relationships have been identified. A linear relationship is generally observed between degradation rate and light intensity, when low intensity light is used. At high light intensity, the degradation rate is independent of the light intensity. For intermediate light intensities, the power-law between light intensity and reaction rate holds with an exponent varying between 0.5-0.8 [209]. Malekshoar, et al. [209], studied the effect of light intensity on the activity of Graphene- $\mathrm{TiO}_{2}$ composite on degradation of phenol, by varying the light intensity between $20-10 \mathrm{~mW} / \mathrm{cm}^{2}$. The authours observed a linear relationship between the intensity and reaction rate at light intensities below $50 \mathrm{~mW} / \mathrm{cm}^{2}$, while at higher intensities the rate increased with a power of 0.7 .

\subsection{Water Matrix}

To determine the suitability of any AOP for wastewater treatment, it is important to evaluate the effect of co-existing susbstances such as organic acids (e.g., acetic and formic acids), natural organic matters (NOM) (e.g., fulvic and humic acids) and inorganic ions (e.g., $\mathrm{Cl}-, \mathrm{NO}_{3}^{-}, \mathrm{CO}_{3}^{2-}$ and $\mathrm{SO}_{4}^{2-}$ on the removal efficiency of pollutants. The water matrix also significantly influence the optimal condition for any degradation process. The presence of co-existing substances could either have a negative or positive influence on the degradation efficiency of a process. The negative influence of co-existing substances may arise from their undesirable reactions with generated radical species and the light scattering ability of some suspendeded solids. Meanwhile, the positive effect of co-existing substances arises due to the oxidation and reduction properties of some of these compounds, which could serve either as oxidants or reductants in the catalytic process. Furthermore, compounds with carboxylic and hydroxy groups could form complexes with high quantum yield, leading to enhanced photo-reduction reaction [210-212]. Tokumura, et al. [212] explored the effect of water matrix on the degradation of carbamazepine and diclofenac using three AOPs: photo-Fenton, photocatalysis and combined oxine and hydrogen peroxide oxidation process. The authors reported an increase in the efficiency of the Fenton process due to additional iron ions from the water matrix. However, the photo-reduction reaction was inhibited by the light scattering effect and complex-formation of co-existing substances. For the photocatalytic and combined ozone and hydrogen peroxide oxdiation process, the scavenging effect of the co-existing substances was a main inhibiting factor to the efficiency of the processes.

\subsection{Comparative Analysis of Graphene-Based Catalytic Process for Degradation of Pharmaceuticals}

The comparative analysis of the identified degradation techniques for degradation of pharmaceuticals by graphene-based catalytic processes, was carried out in terms of efficiency, reaction rate, mineralization rate and the time required to reach $90 \%$ degradation. The result of the analysis is shown in Table 5 . All the five degradation techniques showed very close degradation efficiency above $90 \%$, which confirms the potential of these techniques in pharmaceutical degradation. In terms of the reaction rate for each process, the chemical oxidation process showed the highest average reaction rate, with photocatalysis and electrocatalysis showing very similar degradation rates. The direct degradation and sonocatalytic/sonophotocatalytic processes showed low degradation rates. Comparing the average mineralization of each process, it is observed that electrocatalysis and sonocatalytic processes had the highest potential for conversion of pharmaceuticals to $\mathrm{CO}_{2}$ and water. 
Table 5. Comparative analysis of graphene-based composite techniques for pharmaceutical degradation.

\begin{tabular}{|c|c|c|c|c|}
\hline & $\begin{array}{l}\text { Average Process } \\
\text { Efficiency (\%) }\end{array}$ & $\begin{array}{l}\text { Average Reaction } \\
\text { Rate }\left(\mathrm{min}^{-1}\right)\end{array}$ & $\begin{array}{c}\text { Average } \\
\text { Mineralization (\%) }\end{array}$ & $\begin{array}{l}\text { Average Time to Achieve } \\
90 \% \text { Degradation (min) }\end{array}$ \\
\hline Direct degradation process & 92.0 & 0.002 & - & 1123 \\
\hline Chemical oxidation process & 94.5 & 0.321 & 65 & 69.2 \\
\hline Photocatalysis & 95.1 & 0.177 & 63.15 & 28.4 \\
\hline Electrocatalysis & 91.9 & 0.170 & 81.0 & 56.5 \\
\hline Sonocatalytic/sono-photocatalytic process & 92.5 & 0.048 & 81 & 97.6 \\
\hline
\end{tabular}

The time required to attain $90 \%$ degradation for each process was evaluated using the equation:

$$
t_{0.9}=\frac{2.3035851}{k}
$$

where $k$ is the reaction rate constant for each of the study. The average of the $t_{0.9}$ for each process, showed that photocatalytic process had the lowest required time to achieve $90 \%$ degradation compared to other processes. This was followed by electrocatalysis and chemical oxidation processes.

\section{Future Perspectives}

The excellent catalytic activity of graphene-based composites for pharmaceutical degradation has been discussed in this review. In many of the explored studies, graphene/ graphene derivatives have been used as a minor component of the catalytic materials. However, few studies have shown that composites constituting graphene/graphene oxide as major components have also shown good catalytic activity. It becomes important for the optimal graphene/graphene derivative to be explored and important factors such as cost, sustainability, efficiency in determining the preferred constitution. Also, discussed in this review were mainly bench scale studies with limited studies available for pilot scale studies. With the large volume of bench scale results obtained so far, studies on graphene-based composites for pharmaceutical degradation seems ripe for pilot scale studies, which might set it on the part to full commercialization.

\section{Conclusions}

A review of processes employing graphene-based composites as catalysts for degradation of pharmaceuticals have been presented in this study and five different degradation processes-direct catalytic degradation, chemical oxidation process, photocatalysis, electrocatalytic processes and sonocatalytic/sono-photocatalytic processes-have been identified in the explored literatures. Each of the process showed high degradation efficiencies, with the generation of reactive radical species being responsible for the activity of each process. Incorporation of graphene/graphene derivatives, was observed to enhance the degradation efficiency by improving on the generation of radical species, through improved surface area, light absorption and reduce recombination of generated charge carriers. A key factor in enhancing the activity of the composite is the determination of the optimal weight percentage of graphene required for improving the catalytic activity. Comparative analysis of these techniques showed that while they exhibit similar degradation efficiency, the photocatalytic process requires the least amount of time to attain $90 \%$ degradation, while the electrocatalytic and sonocatalytic processes are the most desirable in terms of mineralization potential.

Author Contributions: Conceptualization, O.C.O. and D.C.O.; Supervision, D.C.O.; writing-original draft, O.C.O.; writing-review and editing, D.C.O. All authors have read and agreed to the published version of the manuscript.

Funding: This research was funded by National Research Foundation (NRF), South Africa, Grant Number [UID109333 and UID 116338]. The APC was funded by the North-West University, South Africa.

Data Availability Statement: Not available. 
Conflicts of Interest: Authors declare no conflict of interest.

\section{References}

1. Lin, L.; Wang, H.; $\mathrm{Xu}, \mathrm{P}$. Immobilized $\mathrm{TiO}_{2}$-reduced graphene oxide nanocomposites on optical fibers as high performance photocatalysts for degradation of pharmaceuticals. Chem. Eng. J. 2017, 310, 389-398. [CrossRef]

2. Xu, Y.; Liu, T.J.; Zhang, Y.; Ge, F.; Steel, R.M.; Sun, L.Y. Advances in technologies for pharmaceuticals and personal care products removal. J. Mater. Chem. A 2017, 5, 12001-12014. [CrossRef]

3. Magureanu, M.; Mandache, N.B.; Parvulescu, V.I. Degradation of pharmaceutical compounds in water by non-thermal plasma treatment. Water Res. 2015, 81, 124-136. [CrossRef]

4. Wongso, V.; Chung, H.K.; Sambudi, N.S.; Sufian, S.; Abdullah, B.; Wirzal, M.D.H.; Ang, W.L. Silica-carbon quantum dots decorated titanium dioxide as sunlight-driven photocatalyst to diminish acetaminophen from aquatic environment. J. Photochem. Photobiol. A Chem. 2020, 394, 112436. [CrossRef]

5. Zur, J.; Michalska, J.; Pinski, A.; Mrozik, A.; Nowak, A. Effects of Low Concentration of Selected Analgesics and Successive Bioaugmentation of the Activated Sludge on its Activity and Metabolic Diversity. Water 2020, 12, 4113. [CrossRef]

6. Bhatia, V.; Malekshoar, G.; Dhir, A.; Ray, A.K. Enhanced photocatalytic degradation of atenolol using graphene $\mathrm{TiO}_{2}$ composite. J. Photochem. Photobiol. A Chem. 2017, 332, 182-187. [CrossRef]

7. Hong, B.; Lin, Q.; Yu, S.; Chen, Y.; Chen, Y.; Chiang, P. Urbanization gradient of selected pharmaceuticals in surface water at a watershed scale. Sci. Total Environ. 2018, 634, 448-458. [CrossRef] [PubMed]

8. Daughton, C.G. Cradle-to-cradle stewardship of drugs for minimizing their environmental disposition while promoting human health. I. Rationale for and avenues toward a green pharmacy. Environ. Health Perspect. 2003, 111, 757-774. [CrossRef]

9. Khan, H.K.; Rehman, M.Y.A.; Malik, R.N. Fate and toxicity of pharmaceuticals in water environment: An insight on their occurrence in South Asia. J. Environ. Manag. 2020, 271, 111030. [CrossRef]

10. Franzellitti, S.; Fabbri, E. Response to Commentary on "Are some invertebrates exquisitely sensitive to the human pharmaceutical fluoxetine?". Aquat. Toxicol. 2014, 146, 264-265. [CrossRef]

11. Du, B.; Haddad, S.P.; Luek, A.; Scott, W.C.; Saari, G.N.; Kristofco, L.A.; Connors, K.A.; Rash, C.; Rasmussen, J.B.; Chambliss, C.K.; et al. Bioaccumulation and trophic dilution of human pharmaceuticals across trophic positions of an effluent-dependent wadeable stream. Philos. Trans. R. Soc. B Biol. Sci. 2014, 369, 20140058. [CrossRef]

12. Gomez, C.F.; Constantine, L.; Moen, M.; Vaz, A.; Wang, W.; Huggett, D.B. Ibuprofen Metabolism in the Liver and Gill of Rainbow Trout, Oncorhynchus mykiss. Bull. Environ. Contam. Toxicol. 2011, 86, 247-251. [CrossRef]

13. Brooks, B.W.; Huggett, D.B.; Boxall, A.B. Pharmaceuticals and personal care products: Research needs for the next decade. Environ. Toxicol. Chem. 2009, 28, 2469. [CrossRef]

14. Ali, I.; Gupta, V.K. Advances in water treatment by adsorption technology. Nat. Protoc. 2006, 1, 2661. [CrossRef]

15. Redding, A.M.; Cannon, F.S.; Snyder, S.A.; Vanderford, B.J. A QSAR-like analysis of the adsorption of endocrine disrupting compounds, pharmaceuticals, and personal care products on modified activated carbons. Water Res. 2009, 43, $3849-3861$. [CrossRef]

16. Valcarcel, Y.; Alonso, S.G.; Rodriguez-Gil, J.L.; Maroto, R.R.; Gil, A.; Catala, M. Analysis of the presence of cardiovascular and analgesic/anti-inflammatory/antipyretic pharmaceuticals in river- and drinking-water of the Madrid Region in Spain. Chemosphere 2011, 82, 1062-1071. [CrossRef] [PubMed]

17. Patel, M.; Kumar, R.; Kushor, K.; Msna, T.; Pittman, C.U.; Mohan, D. Pharmaceuticals of emerging concern in Aquatic Systems: Chemistry, Occurrence, Effects and Removal Methods. Chem. Rev. 2019, 119, 3510-3673. [CrossRef] [PubMed]

18. Mompelat, S.; Le Bot, B.; Thomas, O. Occurrence and fate of pharmaceutical products and by-products, from resource to drinking water. Environ. Int. 2009, 35, 803-814. [CrossRef] [PubMed]

19. Radjenovic, J.; Petrovic, M.; Barcelo, D. Fate and distribution of pharmaceuticals in wastewater and sewage sludge of the conventional activated sludge (CAS) and advanced membrane bioreactor (MBR) treatment. Water Res. 2009, 43, 831-841. [CrossRef]

20. Sayadi, H.; Trivedy, R.K.; Pathak, R.K. Pollution of Pharmaceuticals in Environment. J. Ind. Pollut. Control 2010, $26,89-94$.

21. Robinson, I.; Junqua, G.; Van Coillie, R.; Thomas, O. Trends in the detection of pharmaceutical products, and their impact and mitigation in water and wastewater in North America. Anal. Bioanal. Chem. Res. 2007, 387, 1143-1151. [CrossRef]

22. Fent, K.; Weston, A.A.; Caminada, D. Ecotoxicology of human pharmaceuticals. Aquat. Toxicol. 2006, 76, 122-159. [CrossRef]

23. Kümmerer, K. Pharmaceuticals in the Environment-Scope of the Book and Introduction. In Pharmaceuticals in the Environment: Sources, Fate, Effects and Risks; Kümmerer, K., Ed.; Springer: Berlin/Heidelberg, Germany, 2004; pp. 3-11.

24. Vieno, N.; Sillanpää, M. Fate of diclofenac in municipal wastewater treatment plant-A review. Environ. Int. 2014, 69, 28-39. [CrossRef] [PubMed]

25. Memmert, U.; Peither, A.; Burri, R.; Weber, K.; Schmidt, T.; Sumpter, J.P.; Hartmann, A. Diclofenac: New data on chronic toxicity and bioconcentration in fish. Environ. Toxicol. Chem. 2013, 32, 442-452. [CrossRef] [PubMed]

26. Larsson, D.J.; de Pedro, C.; Paxeus, N.J. Effluent from drug manufactures contains extremely high levels of pharmaceuticals. J. Hazard. Mater. 2007, 148, 751-755. [CrossRef] [PubMed] 
27. Hai, F.I.; Yang, S.; Asif, M.B.; Sencadas, V.; Shawkat, S.; Sanderson-Smith, M.; Gorman, J.; Xu, Z.-Q.; Yamamoto, K. Carbamazepine as a Possible Anthropogenic Marker in Water: Occurrences, Toxicological Effects, Regulations and Removal by Wastewater Treatment Technologies. Water 2018, 10, 107. [CrossRef]

28. De Lange, H.J.; Noordoven, W.; Murk, A.J.; Lürling, M.; Peeters, E.T.H.M. Behavioural responses of Gammarus pulex (Crustacea, Amphipoda) to low concentrations of pharmaceuticals. Aquat. Toxicol. 2006, 78, 209-216. [CrossRef]

29. Nikolai, L.N.; McClure, E.L.; MacLeod, S.L.; Wong, C.S. Stereoisomer quantification of the $\beta$-blocker drugs atenolol, metoprolol, and propranolol in wastewaters by chiral high-performance liquid chromatography-tandem mass spectrometry. J. Chromatogr. A 2006, 1131, 103-109. [CrossRef]

30. Fraysse, B.; Garric, J. Prediction and experimental validation of acute toxicity of beta-blockers in Ceriodaphnia dubia. Environ. Toxicol. Chem. 2005, 24, 2470-2476. [CrossRef]

31. Li, M.-H. Acute toxicity of industrial endocrine-disrupting chemicals, natural and synthetic sex hormones to the freshwater planarian, Dugesia japonica. Toxicol. Environ. Chem. 2013, 95, 984-991. [CrossRef]

32. Forghani, M.; Sadeghi, G.; Peyda, M. The Presence of 17 Beta-Estradiol in the Environment: Health Effects and Increasing Environmental Concerns. Int. J. Epidemiol. Res. 2018, 5, 151-158. [CrossRef]

33. Nassour, C.; Barton, S.J.; Nabhani-Gebara, S.; Saab, Y.; Barker, J. Occurrence of anticancer drugs in the aquatic environment: A systematic review. Environ. Sci. Pollut. Res. 2020, 27, 1339-1347. [CrossRef]

34. Jauković, Z.D.; Grujić, S.D.; Vasiljević, T.M.; Petrović, S.D.; Lausević, M.D. Cardiovascular drugs in environmental waters and wastewaters: Method optimization and real sample analysis. J. AOAC Int. 2014, 97, 1167-1174. [CrossRef]

35. Scheurer, M.; Sacher, F.; Brauch, H.-J. Occurrence of the antidiabetic drug metformin in sewage and surface waters in Germany. J. Environ. Monit. 2009, 11, 1608-1613. [CrossRef]

36. Ikehata, K.; Jodeiri Naghashkar, N.; Gamal El-Din, M. Degradation of Aqueous Pharmaceuticals by Ozonation and Advanced Oxidation Processes: A Review. Ozone Sci. Eng. 2006, 28, 353-414. [CrossRef]

37. Larsen, T.A.; Lienert, J.; Joss, A.; Siegrist, H. How to avoid pharmaceuticals in the aquatic environment. J. Biotechnol. 2004, 113, 295-304. [CrossRef] [PubMed]

38. Khurana, P.; Thatai, S.; Kumar, D. Destruction of recalcitrant nanomaterials contaminants in industrial wastewater. In Emerging and Nanomaterial Contaminants in Wastewater; Elsevier: Amsterdam, The Netherlands, 2019; pp. 137-158.

39. Klavarioti, M.; Mantzavinos, D.; Kassinos, D. Removal of residual pharmaceuticals from aqueous systems by advanced oxidation processes. Environ. Int. 2009, 35, 402-417. [CrossRef] [PubMed]

40. Khataee, A.R.; Kasiri, M.B. Artificial neural networks modeling of contaminated water treatment processes by homogeneous and heterogeneous nanocatalysis. J. Mol. Catal. A Chem. 2010, 331, 86-100. [CrossRef]

41. Linden, K.G.; Mohseni, M. 2.8—Advanced Oxidation Processes: Applications in Drinking Water Treatment. In Comprehensive Water Quality and Purification; Ahuja, S., Ed.; Elsevier: Waltham, MA, USA, 2014; pp. 148-172.

42. de Luna, M.D.G.; Lin, J.C.-T.; Gotostos, M.J.N.; Lu, M.-C. Photocatalytic oxidation of acetaminophen using carbon self-doped titanium dioxide. Sustain. Environ. Res. 2016, 26, 161-167. [CrossRef]

43. Khataee, A.R.; Fathinia, M. Recent Advances in Photocatalytic Processes by Nanomaterials. In New and Future Developments in Catalysis; Elsevier: Amsterdam, The Netherlands, 2013; pp. 267-288.

44. Chong, M.N.; Jin, B.; Chow, C.W.; Saint, C. Recent developments in photocatalytic water treatment technology: A review. Water Res. 2010, 44, 2997-3027. [CrossRef]

45. Wang, F.; Zhu, Y.; Tian, W.; Lv, X.; Zhang, H.; Hu, Z.; Zhang, Y.; Ji, J.; Jiang, W. Co-doped Ni $\mathrm{N}_{2} @ \mathrm{CNT}$ arrays anchored on graphite foam with a hierarchical conductive network for high-performance supercapacitors and hydrogen evolution electrodes. J. Mater. Chem. A 2018, 6, 10490-10496. [CrossRef]

46. Isac, L.; Cazan, C.; Enesca, A.; Andronic, L. Copper Sulfide Based Heterojunctions as Photocatalysts for Dyes Photodegradation. Front. Chem. 2019, 7. [CrossRef]

47. Alenizi, M.A.; Kumar, R.; Aslam, M.; Alseroury, F.A.; Barakat, M.A. Construction of a ternary g- $\mathrm{C}_{3} \mathrm{~N}_{4} / \mathrm{TiO}_{2} @$ polyaniline nanocomposite for the enhanced photocatalytic activity under solar light. Sci. Rep. 2019, 9, 12091. [CrossRef]

48. Kuvarega, A.T.; Mamba, B.B.; Sciences, $\mathrm{M}_{\text {. TiO }}$-based photocatalysis: Toward visible light-responsive photocatalysts through doping and fabrication of carbon-based nanocomposites. Crit. Rev. Solid State Mater. Sci. 2017, 42, 295-346. [CrossRef]

49. Rattan Paul, D.; Nehra, S.P. Graphitic carbon nitride: A sustainable photocatalyst for organic pollutant degradation and antibacterial applications. Environ. Sci. Pollut. Res. 2020. [CrossRef] [PubMed]

50. Darkwah, W.K.; Oswald, K.A. Photocatalytic Applications of Heterostructure Graphitic Carbon Nitride: Pollutant Degradation, Hydrogen Gas Production (water splitting), and $\mathrm{CO}_{2}$ Reduction. Nanoscale Res. Lett. 2019, 14, 234. [CrossRef] [PubMed]

51. Ishikawa, A.; Takata, T.; Kondo, J.N.; Hara, M.; Kobayashi, H.; Domen, K. Oxysulfide $\mathrm{Sm}_{2} \mathrm{Ti}_{2} \mathrm{~S}_{2} \mathrm{O}_{5}$ as a Stable Photocatalyst for Water Oxidation and Reduction under Visible Light Irradiation $(\lambda \leq 650 \mathrm{~nm})$. J. Am. Chem. Soc. 2002, 124, 13547-13553. [CrossRef] [PubMed]

52. Singh, M.; Kumar, A.; Krishnan, V. Influence of different bismuth oxyhalides on the photocatalytic activity of graphitic carbon nitride: A comparative study under natural sunlight. Mater. Adv. 2020, 1, 1262-1272. [CrossRef]

53. Jung, B.; Deng, W.; Li, Y.; Batchelor, B.; Abdel-Wahab, A. Simulated solar light-driven photocatalytic degradation of trichloroethylene in water using BiOBr promoted by sulfite addition. Environ. Sci. Eur. 2020, 32. [CrossRef] 
54. Cosham, S.D.; Celorrio, V.; Kulak, A.N.; Hyett, G. Observation of visible light activated photocatalytic degradation of stearic acid on thin films of tantalum oxynitride synthesized by aerosol assisted chemical vapour deposition. Dalton Trans. 2019, 48, 10619-10627. [CrossRef]

55. Boppana, V.B.R.; Doren, D.J.; Lobo, R.F. A Spinel Oxynitride with Visible-Light Photocatalytic Activity. ChemSusChem 2010, 3 , 814-817. [CrossRef]

56. Mohd Adnan, M.A.; Muhd Julkapli, N.; Amir, M.N.I.; Maamor, A. Effect on different $\mathrm{TiO}_{2}$ photocatalyst supports on photodecolorization of synthetic dyes: A review. Int. J. Environ. Sci. Technol. 2019, 16, 547-566. [CrossRef]

57. Anku, W.W.; Kiarii, E.M.; Sharma, R.; Joshi, G.M.; Shukla, S.K.; Govender, P.P. Photocatalytic degradation of pharmaceuticals using graphene based materials. In A New Generation Material Graphene: Applications in Water Technology; Elsevier: Amsterdam, The Netherlands, 2018; pp. 187-208.

58. Oluwole, A.O.; Omotola, E.O.; Olatunji, O.S. Pharmaceuticals and personal care products in water and wastewater: A review of treatment processes and use of photocatalyst immobilized on functionalized carbon in AOP degradation. BMC Chem. 2020, 14. [CrossRef] [PubMed]

59. Carmalin Sophia, A.; Lima, E.C.; Allaudeen, N.; Rajan, S. Application of graphene based materials for adsorption of pharmaceutical traces from water and wastewater-A review. Desalin. Water Treat. 2016, 57, 27573-27586. [CrossRef]

60. Mester, A.S.; Carvalho, A.P. Photocatalytic degradation of pharmaceuticals carbamazepine, Diclofenac and Sulfamethoxazole by semiconductor and carbon materials: A Review. Molecules. 2019, 24, 3702. [CrossRef] [PubMed]

61. Putri, L.K.; Ong, W.-J.; Chang, W.S.; Chai, S.-P. Heteroatom doped graphene in photocatalysis: A review. Appl. Surf. Sci. 2015, 358, 2-14. [CrossRef]

62. Koe, W.S.; Lee, J.W.; Chong, W.C.; Pang, Y.L.; Sim, L.C. An overview of photocatalytic degradation: Photocatalysts, mechanisms, and development of photocatalytic membrane. Environ. Sci. Pollut. Res. Int. 2020, 27, 2522-2565. [CrossRef]

63. Rani, P.; Jindal, V.K. Designing band gap of graphene by B and N dopant atoms. RSC Adv. 2013, 3, 802-812. [CrossRef]

64. Sturala, J.; Luxa, J.; Pumera, M.; Sofer, Z. Chemistry of Graphene Derivatives: Synthesis, Applications, and Perspectives. Chem. Eur. J. 2018, 24, 5992-6006. [CrossRef]

65. Wang, H.; Maiyalagan, T.; Wang, X. Review on Recent Progress in Nitrogen-Doped Graphene: Synthesis, Characterization, and Its Potential Applications. ACS Catal. 2012, 2, 781-794. [CrossRef]

66. Kumar, P.V.; Bardhan, N.M.; Tongay, S.; Wu, J.; Belcher, A.M.; Grossman, J.C. Scalable enhancement of graphene oxide properties by thermally driven phase transformation. Nat. Chem. 2014, 6, 151-158. [CrossRef]

67. Zhang, S.; Li, B.; Wang, X.; Zhao, G.; Hu, B.; Lu, Z.; Wen, T.; Chen, J.; Wang, X. Recent developments of two-dimensional graphene-based composites in visible-light photocatalysis for eliminating persistent organic pollutants from wastewater. Chem. Eng. J. 2020, 390. [CrossRef]

68. Han, C.; Zhang, N.; Xu, Y.-J. Structural diversity of graphene materials and their multifarious roles in heterogeneous photocatalysis. Nano Today 2016, 11, 351-372. [CrossRef]

69. Ye, L.-H.; Liu, B.-G.; Ding-Sheng, W. Ab initio Molecular Dynamics Study on Small Carbon Nanotubes. Chin. Phys. Lett. 2001, 18, 1496. [CrossRef]

70. Bilal, M.; Rasheed, T.; Mehmood, S.; Tang, H.; Ferreira, L.F.R.; Bharagava, R.N.; Iqbal, H.M.N. Mitigation of environmentallyrelated hazardous pollutants from water matrices using nanostructured materials-A review. Chemosphere 2020, $253,126770$. [CrossRef]

71. Chen, J.; Li, Y.; Huang, L.; Li, C.; Shi, G. High-yield preparation of graphene oxide from small graphite flakes via an improved Hummers method with a simple purification process. Carbon 2015, 81, 826-834. [CrossRef]

72. Dong, L.; Chen, Z.; Lin, S.; Wang, K.; Ma, C.; Lu, H. Reactivity-Controlled Preparation of Ultralarge Graphene Oxide by Chemical Expansion of Graphite. Chem. Mater. 2017, 29, 564-572. [CrossRef]

73. Liu, Z.; Duan, X.; Zhou, X.; Qian, G.; Zhou, J.; Yuan, W. Controlling and formation mechanism of oxygen-containing groups on graphite oxide. Ind. Eng. Chem. Res. 2014, 53, 253-258. [CrossRef]

74. Morimoto, N.; Kubo, T.; Nishina, Y. Tailoring the oxygen content of graphite and reduced graphene oxide for specific applications. Sci. Rep. 2016, 6, 21715. [CrossRef] [PubMed]

75. Peng, L.; Xu, Z.; Liu, Z.; Wei, Y.; Sun, H.; Li, Z.; Zhao, X.; Gao, C. An iron-based green approach to 1-h production of single-layer graphene oxide. Nat. Commun. 2015, 6, 5716. [CrossRef] [PubMed]

76. Pendolino, F.; Armata, N.; Masullo, T.; Cuttitta, A. Temperature influence on the synthesis of pristine graphene oxide and graphite oxide. Mater. Chem. Phys. 2015, 164, 71-77. [CrossRef]

77. Brodie, B. Note sur un nouveau procédé pour la purification et la désagrégation du graphite. J. Ann. Chim. Phys. 1855, 45, 351-353.

78. Staudenmaier, L. Verfahren zur Darstellung der Graphitsäure. Ber. Dtsch. Chem. Ges. 1898, 31, 1481-1487. [CrossRef]

79. Marcano, D.C.; Kosynkin, D.V.; Berlin, J.M.; Sinitskii, A.; Sun, Z.; Slesarev, A.; Alemany, L.B.; Lu, W.; Tour, J.M. Improved Synthesis of Graphene Oxide. ACS Nano 2010, 4, 4806-4814. [CrossRef] [PubMed]

80. Pei, S.; Wei, Q.; Huang, K.; Cheng, H.-M.; Ren, W. Green synthesis of graphene oxide by seconds timescale water electrolytic oxidation. Nat. Commun. 2018, 9, 145. [CrossRef] [PubMed]

81. Muthoosamy, K.; Manickam, S. State of the art and recent advances in the ultrasound-assisted synthesis, exfoliation and functionalization of graphene derivatives. Ultrason. Sonochem. 2017, 39, 478-493. [CrossRef] [PubMed] 
82. Li, L.; Zhang, D.; Deng, J.; Kang, Q.; Liu, Z.; Fang, J.; Gou, Y. Review-Progress of Research on the Preparation of Graphene Oxide via Electrochemical Approaches. J. Electrochem. Soc. 2020, 167, 155519. [CrossRef]

83. Yu, P.; Lowe, S.E.; Simon, G.P.; Zhong, Y.L. Electrochemical exfoliation of graphite and production of functional graphene. Curr. Opin. Colloid Interface Sci. 2015, 20, 329-338. [CrossRef]

84. De Silva, K.K.H.; Huang, H.H.; Joshi, R.K.; Yoshimura, M. Chemical reduction of graphene oxide using green reductants. Carbon 2017, 119, 190-199. [CrossRef]

85. Smith, A.T.; LaChance, A.M.; Zeng, S.; Liu, B.; Sun, L. Synthesis, properties, and applications of graphene oxide/reduced graphene oxide and their nanocomposites. Nano Mater. Sci. 2019, 1, 31-47. [CrossRef]

86. Gholampour, A.; Valizadeh Kiamahalleh, M.; Tran, D.N.H.; Ozbakkaloglu, T.; Losic, D. From Graphene Oxide to Reduced Graphene Oxide: Impact on the Physiochemical and Mechanical Properties of Graphene-Cement Composites. ACS Appl. Mater. Interfaces 2017, 9, 43275-43286. [CrossRef] [PubMed]

87. Venkanna, M.; Chakraborty, A.K. Synthesis and characterizations of graphene oxide and reduced graphene oxide nanosheets. AIP Conf. Proc. 2014, 1591, 574-576. [CrossRef]

88. Minitha, C.R.; Rajendrakumar, R.T. Synthesis and Characterization of Reduced Graphene Oxide. Adv. Mat. Res. 2013, 678, 56-60. [CrossRef]

89. Habte, A.T.; Ayele, D.W. Synthesis and Characterization of Reduced Graphene Oxide (rGO) Started from Graphene Oxide (GO) Using the Tour Method with Different Parameters. Adv. Mater. Sci. Eng. 2019, 2019, 5058163. [CrossRef]

90. Andrijanto, E.; Shoelarta, S.; Subiyanto, G.; Rifki, S. Facile synthesis of graphene from graphite using ascorbic acid as reducing agent. AIP Conf. Proc. 2016, 1725. [CrossRef]

91. De Silva, K.K.H.; Huang, H.-H.; Yoshimura, M. Progress of reduction of graphene oxide by ascorbic acid. Appl. Surf. Sci. 2018, 447, 338-346. [CrossRef]

92. Qu, Y.; Zhang, C.; Li, F.; Chen, J.; Zhou, Q. Photo-reductive defluorination of perfluorooctanoic acid in water. Water Res. 2010, 44, 2939-2947. [CrossRef]

93. Yang, Z.-Z.; Zheng, Q.-B.; Qiu, H.-X.; Li, J.; Yang, J.-H. A simple method for the reduction of graphene oxide by sodium borohydride with $\mathrm{CaCl}_{2}$ as a catalyst. New Carbon Mater. 2015, 30, 41-47. [CrossRef]

94. Chua, C.K.; Pumera, M. Reduction of graphene oxide with substituted borohydrides. J. Mater. Chem. A 2013, 1, 1892-1898. [CrossRef]

95. Shin, H.-J.; Kim, K.K.; Benayad, A.; Yoon, S.-M.; Park, H.K.; Jung, I.-S.; Jin, M.H.; Jeong, H.-K.; Kim, J.M.; Choi, J.-Y.; et al. Efficient Reduction of Graphite Oxide by Sodium Borohydride and Its Effect on Electrical Conductance. Adv. Funct. Mater. 2009, 19, 1987-1992. [CrossRef]

96. Berzina, A.; Tupureina, V.; Orlovs, R.; Saharovs, D.; Bitenieks, J.; Knite, M. Increase of Electrical Conductivity due to Chemical Reduction of Pre-Exfoliated Graphene Oxide by Sodium Borohydride. Adv. Mat. Res. 2015, 1117, 187-190. [CrossRef]

97. Wang, X.; Xing, W.; Yu, B.; Feng, X.; Song, L.; Hu, Y. A facile and cost-effective approach to the reduction of exfoliated graphite oxide using sodium hypophosphite under acidic conditions. J. Mater. Chem. C 2013, 1, 690-694. [CrossRef]

98. Liu, C.; Han, G.; Chang, Y.; Xiao, Y.; Li, Y.; Li, M.; Zhou, H. Capacitive Performances of Reduced Graphene Oxide Hydrogel Prepared by Using Sodium Hypophosphite as Reducer. Chin. J. Chem. 2016, 34, 89-97. [CrossRef]

99. Luo, D.; Zhang, G.; Liu, J.; Sun, X. Evaluation Criteria for Reduced Graphene Oxide. J. Phys. Chem. 2011, 115, 11327-11335. [CrossRef]

100. Agarwal, V.; Zetterlund, P.B. Strategies for reduction of graphene oxide-A comprehensive review. Chem. Eng. J. 2021, 405. [CrossRef]

101. Bhattacharya, G.; Sas, S.; Wadhwa, S.; Mathur, A.; McLaughlin, J.; Roy, S.S. Aloe vera assisted facile green synthesis of reduced graphene oxide for electrochemical and dye removal applications. RSC Adv. 2017, 7, 26680-26688. [CrossRef]

102. Liang, Y.Y.; Wang, H.L.; Casalongue, H.S.; Chen, Z.; Dai, H.J. $\mathrm{TiO}_{2}$ Nanocrystals Grown on Graphene as Advanced Photocatalytic Hybrid Materials. Nano Res. 2010, 3, 701-705. [CrossRef]

103. Williams, G.; Seger, B.; Kamat, P.V. TiO 2 -Graphene Nanocomposites. UV-Assisted Photocatalytic Reduction of Graphene Oxide. ACS Nano 2008, 2, 1487-1491. [CrossRef]

104. Pan, X.; Yang, M.-Q.; Tang, Z.-R.; Xu, Y.-J. Noncovalently Functionalized Graphene-Directed Synthesis of Ultralarge GrapheneBased $\mathrm{TiO}_{2}$ Nanosheet Composites: Tunable Morphology and Photocatalytic Applications. J. Phys. Chem. 2014, 118, 27325-27335. [CrossRef]

105. Khan, M.; Tahir, M.N.; Adil, S.F.; Khan, H.U.; Siddiqui, M.R.H.; Al-warthan, A.A.; Tremel, W. Graphene based metal and metal oxide nanocomposites: Synthesis, properties and their applications. J. Mater. Chem. A 2015, 3, 18753-18808. [CrossRef]

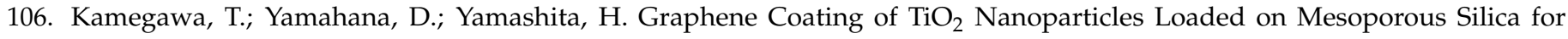
Enhancement of Photocatalytic Activity. J. Phys. Chem. 2010, 114, 15049-15053. [CrossRef]

107. Sun, M.; Li, S.; Zou, J.; Cui, Z.; Zhang, Q.; Schiettekatte, F.; Barba, D.; Liu, B.; Wang, Y. Graphene-Wrapped $\mathrm{ZnMn}_{2} \mathrm{O}_{4} \mathrm{Nanoparticles}$ with Enhanced Performance as Lithium-Ion Battery Anode Materials. Nano 2020, 15. [CrossRef]

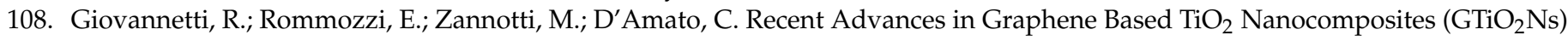
for Photocatalytic Degradation of Synthetic Dyes. Catalysts 2017, 7, 305. [CrossRef]

109. He, F.; Fan, J.; Ma, D.; Zhang, L.; Leung, C.; Chan, H.L. The attachment of $\mathrm{Fe}_{3} \mathrm{O}_{4}$ nanoparticles to graphene oxide by covalent bonding. Carbon 2010, 48, 3139-3144. [CrossRef] 
110. AbdelDayem, H.M.; Salib, B.G.; El-Hosiny, F.I. Facile synthesis of hydrothermal stable hierarchically macro-mesoporous hollow microspheres gamma- $\mathrm{Al}_{2} \mathrm{O}_{3}$-graphene oxide composite: As a new efficient acid-base catalyst for transesterification reaction for biodiesel production. Fuel 2020, 277. [CrossRef]

111. Gao, P.; Liu, J.; Sun, D.D.; Ng, W. Graphene oxide-CdS composite with high photocatalytic degradation and disinfection activities under visible light irradiation. J. Hazard. Mater. 2013, 250-251, 412-420. [CrossRef]

112. Deng, D.R.; Cui, X.Y.; Wu, Q.H.; Zheng, M.S.; Dong, Q.F. In-situ synthesis $\mathrm{TiO}_{2}$ nanosheets@rGO for ultrafast sodium ion storage at both room and low temperatures. J. Alloys Compd. 2020, 835. [CrossRef]

113. Wang, H.; Dai, H. Strongly coupled inorganic-nano-carbon hybrid materials for energy storage. Chem. Soc. Rev. 2013, 42, 3088-3113. [CrossRef]

114. Li, Q.; Mahmood, N.; Zhu, J.; Hou, Y.; Sun, S. Graphene and its composites with nanoparticles for electrochemical energy applications. Nano Today 2014, 9, 668-683. [CrossRef]

115. Liang, Y.; Li, Y.; Wang, H.; Dai, H. Strongly Coupled Inorganic/Nanocarbon Hybrid Materials for Advanced Electrocatalysis. J. Am. Chem. Soc. 2013, 135, 2013-2036. [CrossRef]

116. Acidereli, H.; Cellat, K.; Calimli, M.H.; Sen, F. Palladium/ruthenium supported on graphene oxide (PdRu@GO) as an efficient, stable and rapid catalyst for hydrogen production from DMAB under room conditions. Renew. Energy 2020, 161, 200-206. [CrossRef]

117. Anand, A.; Meena, D.; Bhatnagar, M.C. Synthesis and characterization of flexible PVDF $/ \mathrm{Bi}_{2} \mathrm{Al}_{4} \mathrm{O}_{9} / \mathrm{RGO}$ based piezoelectric materials for nanogenerator application. J. Alloys Compd. 2020, 843. [CrossRef]

118. Cao, P.J.; Cai, Y.Z.; Pawar, D.; Navale, S.T.; Rao, C.N.; Han, S.; Xu, W.Y.; Fang, M.; Liu, X.K.; Zeng, Y.X.; et al. Down to ppb level $\mathrm{NO}_{2}$ detection by $\mathrm{ZnO} / \mathrm{rGO}$ heterojunction based chemiresistive sensors. Chem. Eng. J. 2020, 401. [CrossRef]

119. Ansari, N.; Payami, Z. Synthesis of Magnetic Graphene- $\mathrm{Fe}_{3} \mathrm{O}_{4}$ Nanocomposite by Electrochemical Exfoliation Method. J. Nanostruct. 2020, 10, 39-43. [CrossRef]

120. Aquino, C.B.; Nagaoka, D.A.; Machado, M.M.; Candido, E.G.; da Silva, A.G.M.; Camargo, P.H.C.; Domingues, S.H. Chemical versus electrochemical: What is the best synthesis method to ternary $\mathrm{GO} / \mathrm{WO}_{3} \mathrm{NW} / \mathrm{PAni}$ nanocomposites to improve performance as supercapacitor? Electrochim. Acta 2020, 356. [CrossRef]

121. Wang, H.; Robinson, J.T.; Diankov, G.; Dai, H. Nanocrystal Growth on Graphene with Various Degrees of Oxidation. J. Am. Chem. Soc. 2010, 132, 3270-3271. [CrossRef]

122. Huang, X.; Boey, F.; Zhang, H.U.A. A Brief Review on Graphene-Nanoparticle Composites. Cosmos 2011, 06, 159-166. [CrossRef]

123. Alhumaimess, M.S.; Alsohaimi, I.H.; Alshammari, H.M.; Aldosari, O.F.; Hassan, H.M.A. Synthesis of gold and palladium nanoparticles supported on $\mathrm{CuO} / \mathrm{rGO}$ using imidazolium ionic liquid for $\mathrm{CO}$ oxidation. Res. Chem. Intermed. 2020, 46, 5499-5516. [CrossRef]

124. Liu, J.; Chen, K.-Y.; Wang, J.; Du, M.; Gao, Z.-Y.; Song, C.-X. Preparation and Photocatalytic Properties of N-Doped Graphene/TiO 2 Composites. J. Chem. 2020, 2020, 1-10. [CrossRef]

125. Mahmood, N.; Zhang, C.; Liu, F.; Zhu, J.; Hou, Y. Hybrid of $\mathrm{Co}_{3} \mathrm{Sn}_{2} @$ Co Nanoparticles and Nitrogen-Doped Graphene as a Lithium Ion Battery Anode. ACS Nano 2013, 7, 10307-10318. [CrossRef] [PubMed]

126. Saroyan, H.S.; Bele, S.; Giannakoudakis, D.A.; Samanidou, V.F.; Bandosz, T.J.; Deliyanni, E.A. Degradation of endocrine disruptor, bisphenol-A, on an mixed oxidation state manganese oxide/modified graphite oxide composite: A role of carbonaceous phase. $J$. Colloid Interface Sci. 2019, 539, 516-524. [CrossRef]

127. Song, C.; Guo, B.-B.; Sun, X.-F.; Wang, S.-G.; Li, Y.-T. Enrichment and degradation of tetracycline using three-dimensional graphene $/ \mathrm{MnO}_{2}$ composites. Chem. Eng. J. 2019, 358, 1139-1146. [CrossRef]

128. Xiao, R.; Luo, Z.; Wei, Z.; Luo, S.; Spinney, R.; Yang, W.; Dionysiou, D.D. Activation of peroxymonosulfate/persulfate by nanomaterials for sulfate radical-based advanced oxidation technologies. Curr. Opin. Chem. Eng. 2018, 19, 51-58. [CrossRef]

129. Wang, J.; Wang, S. Activation of persulfate (PS) and peroxymonosulfate (PMS) and application for the degradation of emerging contaminants. Chem. Eng. J. 2018, 334, 1502-1517. [CrossRef]

130. Chen, H.; Carroll, K.C. Metal-free catalysis of persulfate activation and organic-pollutant degradation by nitrogen-doped graphene and aminated graphene. Environ. Pollut. 2016, 215, 96-102. [CrossRef] [PubMed]

131. Hao, P.; Hu, M.; Xing, R.; Zhou, W. Synergistic degradation of methylparaben on $\mathrm{CuFe}_{2} \mathrm{O}_{4}-\mathrm{rGO}$ composite by persulfate activation. J. Alloys Compd. 2020, 823. [CrossRef]

132. Jiang, L.; Xu, X.; Yuan, J.; Zuo, Y.; Tao, Y.; Yao, D.; He, G.; Chen, H. Heterogeneous activation of persulfate for the degradation of bisphenol A with $\mathrm{Ni}_{2} \mathrm{SnO}_{4}-\mathrm{RGO}$. New J. Chem. 2020, 44, 6355-6361. [CrossRef]

133. Vieira, O.; Ribeiro, R.S.; Pedrosa, M.; Lado Ribeiro, A.R.; Silva, A.M.T. Nitrogen-doped reduced graphene oxide-PVDF nanocomposite membrane for persulfate activation and degradation of water organic micropollutants. Chem. Eng. J. 2020, 402. [CrossRef]

134. Yang, L.; Xu, L.; Bai, X.; Jin, P. Enhanced visible-light activation of persulfate by $\mathrm{Ti}^{3+}$ self-doped $\mathrm{TiO}_{2} /$ graphene nanocomposite $^{3}$ for the rapid and efficient degradation of micropollutants in water. J. Hazard. Mater. 2019, 365, 107-117. [CrossRef]

135. Fan, Y.; Zhou, Z.Y.; Feng, Y.; Zhou, Y.; Wen, L.; Shih, K.M. Degradation mechanisms of ofloxacin and cefazolin using peroxymonosulfate activated by reduced graphene oxide- $\mathrm{CoFe}_{2} \mathrm{O}_{4}$ composites. Chem. Eng. J. 2020, 383, ARTN 123056. [CrossRef] 
136. Solis, R.R.; Mena, I.F.; Nadagouda, M.N.; Dionysiou, D.D. Adsorptive interaction of peroxymonosulfate with graphene and catalytic assessment via non-radical pathway for the removal of aqueous pharmaceuticals. J. Hazard. Mater. 2020, $384,121340$. [CrossRef] [PubMed]

137. Chen, L.; Ding, D.; Liu, C.; Cai, H.; Qu, Y.; Yang, S.; Gao, Y.; Cai, T. Degradation of norfloxacin by $\mathrm{CoFe}_{2} \mathrm{O}_{4}-\mathrm{GO}_{\text {composite coupled }}$ with peroxymonosulfate: A comparative study and mechanistic consideration. Chem. Eng. J. 2018, 334, 273-284. [CrossRef]

138. Monteagudo, J.M.; Durán, A.; San Martín, I.; Carrillo, P. Effect of sodium persulfate as electron acceptor on antipyrine degradation by solar $\mathrm{TiO}_{2}$ or $\mathrm{TiO}_{2} / \mathrm{rGO}$ photocatalysis. Chem. Eng. J. 2019, 364, 257-268. [CrossRef]

139. Park, C.M.; Heo, J.; Wang, D.; Su, C.; Yoon, Y. Heterogeneous activation of persulfate by reduced graphene oxide-elemental silver/magnetite nanohybrids for the oxidative degradation of pharmaceuticals and endocrine disrupting compounds in water. Appl. Catal. B 2018, 225, 91-99. [CrossRef]

140. Zuo, W.; Wang, X.; Zhang, D.; Sun, Y.; Xu, J.; Guo, P. Performance and Mechanism of GO-MCM-Fe Composite Catalyst Activating Persulfate to Remove Levofloxacin Hydrochloride in Water. Water Air Soil Pollut. 2019, 230, 255. [CrossRef]

141. Peng, G.; Zhang, M.; Deng, S.; Shan, D.; He, Q.; Yu, G. Adsorption and catalytic oxidation of pharmaceuticals by nitrogen-doped reduced graphene oxide $/ \mathrm{Fe}_{3} \mathrm{O}_{4}$ nanocomposite. Chem. Eng. J. 2018, 341, 361-370. [CrossRef]

142. Kang, J.; Zhang, H.; Duan, X.; Sun, H.; Tan, X.; Wang, S. Nickel in hierarchically structured nitrogen-doped graphene for robust and promoted degradation of antibiotics. J. Clean. Prod. 2019, 218, 202-211. [CrossRef]

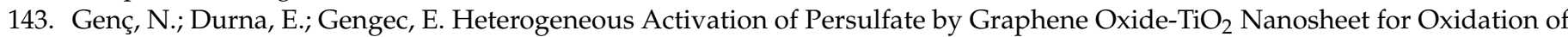
Diclofenac: Optimization by Central Composite Design. Water Air Soil Pollut. 2018, 229, 330. [CrossRef]

144. Fanourakis, S.K.; Pena-Bahamonde, J.; Bandara, P.C.; Rodrigues, D.F. Nano-based adsorbent and photocatalyst use for pharmaceutical contaminant removal during indirect potable water reuse. NPJ Clean Water 2020, 3, ARTN 1. [CrossRef]

145. Bhatia, V.; Manoli, K.; Dhir, A.; Ray, A.K. Response surface optimization of the photocatalytic degradation of atenolol using immobilized graphene-TiO 2 composite. Can. J. Chem. Eng. 2020, 98, 1767-1775. [CrossRef]

146. Cheshme Khavar, A.H.; Moussavi, G.; Mahjoub, A.R. The preparation of $\mathrm{TiO}_{2} @ \mathrm{rGO}$ nanocomposite efficiently activated with UVA/LED and $\mathrm{H}_{2} \mathrm{O}_{2}$ for high rate oxidation of acetaminophen: Catalyst characterization and acetaminophen degradation and mineralization. Appl. Surf. Sci. 2018, 440, 963-973. [CrossRef]

147. Bilgin Simsek, E.; Kilic, B.; Asgin, M.; Akan, A. Graphene oxide based heterojunction $\mathrm{TiO}_{2}-\mathrm{ZnO}$ catalysts with outstanding photocatalytic performance for bisphenol-A, ibuprofen and flurbiprofen. J. Ind. Eng. Chem. 2018, 59, 115-126. [CrossRef]

148. Kumar, A.; Sharma, G.; Naushad, M.; Ahamad, T.; Veses, R.C.; Stadler, F.J. Highly visible active $\mathrm{Ag}_{2} \mathrm{CrO}_{4} / \mathrm{Ag} / \mathrm{BiFeO}_{3} @ \mathrm{RGO}$ nano-junction for photoreduction of $\mathrm{CO}_{2}$ and photocatalytic removal of ciprofloxacin and bromate ions: The triggering effect of Ag and RGO. Chem. Eng. J. 2019, 370, 148-165. [CrossRef]

149. Kumar, A.; Sharma, S.K.; Sharma, G.; Al-Muhtaseb, A.A.H.; Naushad, M.; Ghfar, A.A.; Stadler, F.J. Wide spectral degradation of Norfloxacin by $\mathrm{Ag} @ \mathrm{BiPO}_{4} / \mathrm{BiOBr} / \mathrm{BiFeO}_{3}$ nano-assembly: Elucidating the photocatalytic mechanism under different light sources. J. Hazard. Mater. 2019, 364, 429-440. [CrossRef]

150. Xu, G.; Li, M.; Wang, Y.; Zheng, N.; Yang, L.; Yu, H.; Yu, Y. A novel Ag-BiOBr-rGO photocatalyst for enhanced ketoprofen degradation: Kinetics and mechanisms. Sci. Total Environ. 2019, 678, 173-180. [CrossRef] [PubMed]

151. Mohan, H.; Lim, J.M.; Lee, S.W.; Cho, M.; Park, Y.J.; Seralathan, K.K.; Oh, B.T. $V_{2} \mathrm{O}_{5} / \mathrm{RGO} / \mathrm{Pt}$ nanocomposite on oxytetracycline degradation and pharmaceutical effluent detoxification. J. Chem. Technol. Biotechnol. 2019, 95, 297-307. [CrossRef]

152. Dittrich, H.; Stadler, A.; Topa, D.; Schimper, H.-J.; Basch, A. Progress in sulfosalt research. Phys. Status Solidi A 2009, 206, 1034-1041. [CrossRef]

153. Che, W.; Luo, Y.; Deng, F.; Zhang, A.; Zhao, L.; Luo, X.; Ruan, Q. Facile solvothermal fabrication of cubic-like reduced graphene oxide $/ \operatorname{AgIn}_{5} \mathrm{~S}_{8}$ nanocomposites with anti-photocorrosion and high visible-light photocatalytic performance for highly-efficient treatment of nitrophenols and real pharmaceutical wastewater. Appl. Catal. A Gen. 2018, 565, 170-180. [CrossRef]

154. Fu, K.; Pan, Y.; Ding, C.; Shi, J.; Deng, H. Reduced Graphene Oxide/ZnIn $2 \mathrm{~S}_{4}$ Nanocomposite Photocatalyst with Enhanced Photocatalytic Performance for the Degradation of Naproxen under Visible Light Irradiation. Catalysts 2020, 10, 710. [CrossRef]

155. Rajendran, R.; Shrestha, L.K.; Minami, K.; Subramanian, M.; Jayavel, R.; Ariga, K. Dimensionally integrated nanoarchitectonics for a novel composite from $0 \mathrm{D}, 1 \mathrm{D}$, and $2 \mathrm{D}$ nanomaterials: $\mathrm{RGO} / \mathrm{CNT} / \mathrm{CeO}_{2}$ ternary nanocomposites with electrochemical performance. J. Mater. Chem. A 2014, 2, 18480-18487. [CrossRef]

156. Arumugam, M.; Lee, S.J.; Begildayeva, T.; Naik, S.S.; Yu, Y.; Lee, H.; Theerthagiri, J.; Choi, M.Y. Enhanced photocatalytic activity at multidimensional interface of $1 \mathrm{D}-\mathrm{Bi}_{2} \mathrm{~S}_{3} @ 2 \mathrm{D}-\mathrm{GO} / 3 \mathrm{D}-\mathrm{BiOI}$ ternary nanocomposites for tetracycline degradation under visible-light. J. Hazard. Mater. 2021, 404, 123868. [CrossRef]

157. Kumar, A.; Kumari, A.; Sharma, G.; Du, B.; Naushad, M.; Stadler, F.J. Carbon quantum dots and reduced graphene oxide modified self-assembled $\mathrm{S}_{3} \mathrm{C}_{3} \mathrm{~N}_{4} / \mathrm{B} @ \mathrm{C}_{3} \mathrm{~N}_{4}$ metal-free nano-photocatalyst for high performance degradation of chloramphenicol. J. Mol. Liq. 2020, 300. [CrossRef]

158. Kumar, A.; Sharma, G.; Naushad, M.; Al-Muhtaseb, A.H.; Kumar, A.; Hira, I.; Ahamad, T.; Ghfar, A.A.; Stadler, F.J. Visible photodegradation of ibuprofen and 2,4-D in simulated waste water using sustainable metal free-hybrids based on carbon nitride and biochar. J. Environ. Manag. 2019, 231, 1164-1175. [CrossRef]

159. Donga, C.; Mishra, S.B.; Abd-El-Aziz, A.S.; Mishra, A.K. Advances in Graphene-Based Magnetic and Graphene-Based/TiO 2 Nanoparticles in the Removal of Heavy Metals and Organic Pollutants from Industrial Wastewater. J. Inorg. Organomet. Polym. Mater. 2020. [CrossRef] 
160. El-Fawal, E.M.; Younis, S.A.; Zaki, T. Designing $\mathrm{AgFeO}$-graphene $/ \mathrm{Cu}_{2}(\mathrm{BTC})_{3} \mathrm{MOF}$ heterojunction photocatalysts for enhanced treatment of pharmaceutical wastewater under sunlight. J. Photochem. Photobiol. A Chem. 2020, 401, 112746. [CrossRef]

161. El-Maraghy, C.M.; El-Borady, O.M.; El-Naem, O.A. Effective Removal of Levofloxacin from Pharmaceutical Wastewater Using Synthesized Zinc Oxide, Graphen Oxide Nanoparticles Compared with their Combination. Sci. Rep. 2020, 10, 5914. [CrossRef] [PubMed]

162. Mohan, H.; Selvaraj, D.; Kuppusamy, S.; Venkatachalam, J.; Park, Y.J.; Seralathan, K.K.; Oh, B.T. E-Waste Based V $2 \mathrm{O}_{5} / \mathrm{RGO}_{\mathrm{Pt}}$ Nanocomposite for Photocatalytic Degradation of Oxytetracycline. Environ. Prog. Sustain. Energy 2018, 38, 13123. [CrossRef]

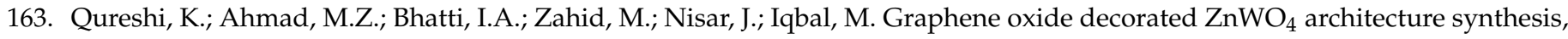
characterization and photocatalytic activity evaluation. J. Mol. Liq. 2019, 285, 778-789. [CrossRef]

164. Entezami, N.; Farhadian, M.; Davari, N. Removal of metronidazole antibiotic pharmaceutical from aqueous solution using $\mathrm{TiO}_{2} / \mathrm{Fe}_{2} \mathrm{O}_{3} / \mathrm{GO}$ photocatalyst: Experimental study on the effects of mineral salts. Adv. Environ. Technol. 2019, 5, 55-65. [CrossRef]

165. Shinde, Y.; Wadhai, S.; Ponkshe, A.; Kapoor, S.; Thakur, P. Decoration of Pt on the metal free $\mathrm{RGO}^{-T i O_{2}}$ composite photocatalyst for the enhanced photocatalytic hydrogen evolution and photocatalytic degradation of pharmaceutical pollutant $\beta$ blocker. Int. J. Hydrogen Energy 2018, 43, 4015-4027. [CrossRef]

166. Esmaeili, A.; Entezari, M.H. Cubic Ag/AgBr-graphene oxide nanocomposite: Sono-synthesis and use as a solar photocatalyst for the degradation of DCF as a pharmaceutical pollutant. RSC Adv. 2015, 5, 97027-97035. [CrossRef]

167. Morales-Torres, S.; Pastrana-Martinez, L.M.; Figueiredo, J.L.; Faria, J.L.; Silva, A.M.T. Graphene oxide-P25 photocatalysts for degradation of diphenhydramine pharmaceutical and methyl orange dye. Appl. Surf. Sci. 2013, 275, 361-368. [CrossRef]

168. Pastrana-Martínez, L.M.; Morales-Torres, S.; Likodimos, V.; Figueiredo, J.L.; Faria, J.L.; Falaras, P.; Silva, A.M.T. Advanced nanostructured photocatalysts based on reduced graphene oxide- $\mathrm{TiO}_{2}$ composites for degradation of diphenhydramine pharmaceutical and methyl orange dye. Appl. Catal. B 2012, 123-124, 241-256. [CrossRef]

169. Xu, P.; Wang, P.; Wang, Q.; Wei, R.; Li, Y.; Xin, Y.; Zheng, T.; Hu, L.; Wang, X.; Zhang, G. Facile synthesis of Ag $2 \mathrm{O} / \mathrm{ZnO} / \mathrm{rGO}$ heterojunction with enhanced photocatalytic activity under simulated solar light: Kinetics and mechanism. J. Hazard. Mater. 2021, 403, 124011. [CrossRef]

170. Ali, A.; Shoeb, M.; Li, B.; Khan, M.A. Enhanced Photcatalytic Degradation of Antibiotic Drug and Dye Pollutants by graphene Ordered Mesoporous Silica (SBA15)/ $\mathrm{TiO}_{2}$ Nanocomposite Under Visible-Light Irradiation. J. Mol. Liq. 2020, 114696. [CrossRef]

171. Hu, Y.; Yang, Y.; Zhang, J.; Jin, S.; Zheng, H. Efficient adsorption and full spectrum photocatalytic degradation of low concentration PPCPs promoted by graphene $/ \mathrm{TiO}_{2}$ nanowires hybrid structure in 3D hydrogel networks. RSC Adv. 2020, 10, 27050-27057. [CrossRef]

172. Zhao, W.; Duan, J.; Ji, B.; Ma, L.; Yang, Z. Novel formation of large area $\mathrm{N}-\mathrm{TiO}_{2}$ /graphene layered materials and enhanced photocatalytic degradation of antibiotics. J. Environ. Chem. Eng. 2020, 8. [CrossRef]

173. Nourieh, N.; Nabizadeh, R.; Faramarzi, M.A.; Nasseri, S.; Yaghmaeian, K.; Mahmoudi, B.; Alimohammadi, M.; Khoobi, M. Photocatalytic degradation of ketoconazole by Z-scheme $\mathrm{Ag}_{3} \mathrm{PO}_{4}$ /graphene oxide: Response surface modeling and optimization. Environ. Sci. Pollut. Res. Int. 2020, 27, 250-263. [CrossRef]

174. Liu, X.; Ji, H.; Li, S.; Liu, W. Graphene modified anatase/titanate nanosheets with enhanced photocatalytic activity for efficient degradation of sulfamethazine under simulated solar light. Chemosphere 2019, 233, 198-206. [CrossRef]

175. Sayadi, M.H.; Sobhani, S.; Shekari, H. Photocatalytic degradation of azithromycin using $\mathrm{GO}_{\mathrm{O}} \mathrm{Fe}_{3} \mathrm{O}_{4} / \mathrm{ZnO} / \mathrm{SnO}_{2}$ nanocomposites. J. Clean. Prod. 2019, 232, 127-136. [CrossRef]

176. Moztahida, M.; Jang, J.; Nawaz, M.; Lim, S.R.; Lee, D.S. Effect of rGO loading on $\mathrm{Fe}_{3} \mathrm{O}_{4}$ : A visible light assisted catalyst material for carbamazepine degradation. Sci. Total Environ. 2019, 667, 741-750. [CrossRef] [PubMed]

177. Soltani, T.; Tayyebi, A.; Lee, B.K. Photolysis and photocatalysis of tetracycline by sonochemically heterojunctioned BiVO4/reduced graphene oxide under visible-light irradiation. J. Environ. Manag. 2019, 232, 713-721. [CrossRef] [PubMed]

178. Cheshme Khavar, A.H.; Moussavi, G.; Mahjoub, A.; Yaghmaeian, K.; Srivastava, V.; Sillanpää, M.; Satari, M. Novel magnetic $\mathrm{Fe}_{3} \mathrm{O}_{4} @ \mathrm{rGO} @ \mathrm{ZnO}$ onion-like microspheres decorated with Ag nanoparticles for the efficient photocatalytic oxidation of metformin: Toxicity evaluation and insights into the mechanisms. Catal. Sci. Technol. 2019, 9, 5819-5837. [CrossRef]

179. Rostami, M.; Zamani, R.M.; Aghajanzadeh, K.M.; Danafar, H. Sol-gel synthesis and characterization of zinc ferrite-graphene nano-hybrids for photo-catalytic degradation of the paracetamol. J. Pharm. Investig. 2017, 48, 657-664. [CrossRef]

180. Brillas, E.; Sirés, I.; Oturan, M.A. Electro-Fenton process and related electrochemical technologies based on Fenton's reaction chemistry. Chem. Rev. 2009, 109, 6570-6631. [CrossRef]

181. Martinez-Huitle, C.A.; Rodrigo, M.A.; Sires, I.; Scialdone, O. Single and Coupled Electrochemical Processes and Reactors for the Abatement of Organic Water Pollutants: A Critical Review. Chem. Rev. 2015, 115, 13362-13407. [CrossRef]

182. Divyapriya, G.; Srinivasan, R.; Nambi, I.M.; Senthilnathan, J. Highly active and stable ferrocene functionalized graphene encapsulated carbon felt array-A novel rotating disc electrode for electro-Fenton oxidation of pharmaceutical compounds. Electrochim. Acta 2018, 283, 858-870. [CrossRef]

183. Deng, F.X.; Garcia-Rodriguez, O.; Olvera-Vargas, H.; Qiu, S.; Lefebvre, O.; Yang, J.X. Iron-foam as a heterogeneous catalyst in the presence of tripolyphosphate electrolyte for improving electro-Fenton oxidation capability. Electrochim. Acta 2018, 272, 176-183. [CrossRef] 
184. Garcia-Segura, S.; Garrido, J.A.; Rodriguez, R.M.; Cabot, P.L.; Centellas, F.; Arias, C.; Brillas, E. Mineralization of flumequine in acidic medium by electro-Fenton and photoelectro-Fenton processes. Water Res. 2012, 46, 2067-2076. [CrossRef]

185. Wang, Y.; Zhao, G.; Chai, S.; Zhao, H.; Wang, Y. Three-dimensional homogeneous ferrite-carbon aerogel: One pot fabrication and enhanced electro-Fenton reactivity. ACS Appl. Mater. Interfaces 2013, 5, 842-852. [CrossRef]

186. Dong, P.; Liu, W.J.; Wang, S.J.; Wang, H.L.; Wang, Y.Q.; Zhao, C.C. In suit synthesis of $\mathrm{Fe}_{3} \mathrm{O}_{4}$ on carbon fiber paper@polyaniline substrate as novel self-supported electrode for heterogeneous electro-Fenton oxidation. Electrochim. Acta 2019, $308,54-63$. [CrossRef]

187. Zhao, H.Y.; Wang, Y.J.; Wang, Y.B.; Cao, T.C.; Zhao, G.H. Electro-Fenton oxidation of pesticides with a novel $\mathrm{Fe}_{3} \mathrm{O}_{4} @ \mathrm{Fe}_{2} \mathrm{O}_{3} /$ activated carbon aerogel cathode: High activity, wide pH range and catalytic mechanism. Appl. Catal. B 2012, 125, 120-127. [CrossRef]

188. Fernández-Sáez, N.; Villela-Martinez, D.E.; Carrasco-Marín, F.; Pérez-Cadenas, A.F.; Pastrana-Martínez, L.M. Heteroatom-doped graphene aerogels and carbon-magnetite catalysts for the heterogeneous electro-Fenton degradation of acetaminophen in aqueous solution. J. Catal. 2019, 378, 68-79. [CrossRef]

189. Görmez, F.; Görmez, Ö.; Gözmen, B.; Kalderis, D. Degradation of chloramphenicol and metronidazole by electro-Fenton process using graphene oxide- $\mathrm{Fe}_{3} \mathrm{O}_{4}$ as heterogeneous catalyst. J. Environ. Chem. Eng. 2019, 7, 102990. [CrossRef]

190. Wang, Y.; Zhang, H.; Li, B.; Yu, M.; Zhao, R.; Xu, X.; Cai, L. $\gamma$-FeOOH graphene polyacrylamide carbonized aerogel as air-cathode in electro-Fenton process for enhanced degradation of sulfamethoxazole. Chem. Eng. J. 2019, 359, 914-923. [CrossRef]

191. Mi, X.; Han, J.; Sun, Y.; Li, Y.; Hu, W.; Zhan, S. Enhanced catalytic degradation by using RGO-Ce/WO 3 nanosheets modified CF as electro-Fenton cathode: Influence factors, reaction mechanism and pathways. J. Hazard. Mater. 2019, 367, 365-374. [CrossRef]

192. Yu, S.; Gao, Y.; Khan, R.; Liang, P.; Zhang, X.; Huang, X. Electrospun PAN-based graphene/SnO $\mathrm{S}_{2}$ carbon nanofibers as anodic electrocatalysis microfiltration membrane for sulfamethoxazole degradation. J. Membr. Sci. 2020, 614, 118368. [CrossRef]

193. Yang, Y.; Xu, L.; Li, W.; Fan, W.; Song, S.; Yang, J. Adsorption and degradation of sulfadiazine over nanoscale zero-valent iron encapsulated in three-dimensional graphene network through oxygen-driven heterogeneous Fenton-like reactions. Appl. Catal. $B$ 2019, 259, 118057. [CrossRef]

194. Divyapriya, G.; Nambi, I.; Senthilnathan, J. Ferrocene functionalized graphene based electrode for the electro-Fenton oxidation of ciprofloxacin. Chemosphere 2018, 209, 113-123. [CrossRef]

195. Zarei, M.; Beheshti Nahand, F.; Khataee, A.; Hasanzadeh, A. Removal of nalidixic acid from aqueous solutions using a cathode containing three-dimensional graphene. J. Water Process Eng. 2019, 32, 100978. [CrossRef]

196. Kumar, A.; Omar, R.A.; Verma, N. Efficient electro-oxidation of diclofenac persistent organic pollutant in wastewater using carbon film-supported Cu-rGO electrode. Chemosphere 2020, 248, 126030. [CrossRef]

197. Mirzazadeh, H.; Lashanizadegan, $\mathrm{M} . \mathrm{Ag}_{2} \mathrm{O} / \mathrm{CdO} / \mathrm{CeO}_{2} /$ reduced graphene oxide: Synthesis, characterization and its application as catalyst for sulfasalazine, diclofenac and phenol degradation under ultrasonic irradiation. Mater. Res. Express 2019, 6, 065008. [CrossRef]

198. Lee, G.; Chu, K.H.; Al-Hamadani, Y.A.J.; Park, C.M.; Jang, M.; Heo, J.; Her, N.; Kim, D.H.; Yoon, Y. Fabrication of grapheneoxide/beta- $\mathrm{Bi}_{2} \mathrm{O}_{3} / \mathrm{TiO}_{2} / \mathrm{Bi}_{2} \mathrm{Ti}_{2} \mathrm{O}_{7}$ heterojuncted nanocomposite and its sonocatalytic degradation for selected pharmaceuticals. Chemosphere 2018, 212, 723-733. [CrossRef]

199. Moradi, S.; Sobhgol, S.A.; Hayati, F.; Isari, A.A.; Kakavandi, B.; Bashardoust, P.; Anvaripour, B. Performance and reaction mechanism of $\mathrm{MgO} / \mathrm{ZnO} /$ Graphene ternary nanocomposite in coupling with LED and ultrasound waves for the degradation of sulfamethoxazole and pharmaceutical wastewater. Sep. Purif. Technol. 2020, 251, ARTN 117373. [CrossRef]

200. Akpotu, S.O.; Oseghe, E.O.; Ayanda, O.S.; Skelton, A.A.; Msagati, T.A.M.; Ofomaja, A.E. Photocatalysis and biodegradation of pharmaceuticals in wastewater: Effect of abiotic and biotic factors. Clean Technol. Environ. Policy 2019, 21, 1701-1721. [CrossRef]

201. Tayeb, A.; Hussein, D. Synthesis of $\mathrm{TiO}_{2}$ Nanoparticles and Their Photocatalytic Activity for Methylene Blue. Am. J. Nanomater. 2015, 3, 57-63. [CrossRef]

202. Kaur, H.; Dahake, R.; Maddigapu, P.R.; Hippargi, G.; Pophali, G.R.; Bansiwal, A. Enhanced photocatalytic degradation of antimicrobial triclosan using $\mathrm{rGO}-\mathrm{TiO}_{2}$ composite under natural solar illumination. J. Mater. Sci. Mater. Electron. 2020, 31, 6045-6058. [CrossRef]

203. Song, J.; Zhen, X.; Chang, C.-T. Hydrothermal Synthesis of Graphene and Titanium Dioxide Nanotubes by a One-Step Method for the Photocatalytic Degradation of Amoxicillin. Nanosci. Nanotechnol. Lett. 2016, 8, 113-119. [CrossRef]

204. Fujishima, A.; Zhang, X.; Tryk, D.A. $\mathrm{TiO}_{2}$ photocatalysis and related surface phenomena. Surf. Sci. Rep. 2008, 63, 515-582. [CrossRef]

205. Choina, J.; Kosslick, H.; Fischer, C.; Flechsig, G.U.; Frunza, L.; Schulz, A. Photocatalytic decomposition of pharmaceutical ibuprofen pollutions in water over titania catalyst. Appl. Catal. B 2013, 129, 589-598. [CrossRef]

206. Azim, M.B.; Nargis, F.; Dhar, S.; Qadir, M.; Gafur, M.; Asw, K.; Gulshan, F. Effect of Dissolved Oxygen Content on Photocatalytic Performance of Graphene Oxide; Elsevier: Amsterdam, The Netherlands, 2018.

207. Lee, H.; Park, S.H.; Kim, B.H.; Kim, S.-J.; Kim, S.-C.; Seo, S.-G.; Jung, S.-C. Contribution of Dissolved Oxygen to Methylene Blue Decomposition by Hybrid Advanced Oxidation Processes System. Int. J. Photoenergy 2012, 2012, 305989. [CrossRef]

208. Subramanian, M.; Kannan, A. Effect of dissolved oxygen concentration and light intensity on photocatalytic degradation of phenol. Korean J. Chem. Eng. 2008, 25, 1300-1308. [CrossRef]

209. Malekshoar, G.; Pal, K.; He, Q.; Yu, A.; Ray, A.K. Enhanced Solar Photocatalytic Degradation of Phenol with Coupled GrapheneBased Titanium Dioxide and Zinc Oxide. Ind. Eng. Chem. Res. 2014, 53, 18824-18832. [CrossRef] 
210. Zanta, C.L.P.S.; Friedrich, L.C.; Machulek, A.; Higa, K.M.; Quina, F.H. Surfactant degradation by a catechol-driven Fenton reaction. J. Hazard. Mater. 2010, 178, 258-263. [CrossRef] [PubMed]

211. Araña, J.; Tello Rendón, E.; Doña Rodríguez, J.M.; Herrera Melián, J.A.; González Díaz, O.; Pérez Peña, J. Highly concentrated phenolic wastewater treatment by the Photo-Fenton reaction, mechanism study by FTIR-ATR. Chemosphere 2001, 44, 1017-1023. [CrossRef]

212. Tokumura, M.; Sugawara, A.; Raknuzzaman, M.; Habibullah-Al-Mamun, M.; Masunaga, S. Comprehensive study on effects of water matrices on removal of pharmaceuticals by three different kinds of advanced oxidation processes. Chemosphere 2016, 159, 317-325. [CrossRef] [PubMed] 